\title{
Simple Solar Spectral Model for Direct and Diffuse Irradiance on Horizontal and Tilted Planes at the Earth's Surface for Cloudless Atmospheres
}

\author{
R. Bird \\ C. Riordan
}

December 1984

Prepared under Task No. 3434.10

FTP No. 460

Solar Energy Research Institute

A Division of Midwest Research Institute

1617 Cole Boulevard

Golden, Colorado 80401

Prepared for the

U.S. Department of Energy

Contract No. DE-AC02-83CH10093 


\section{NOTICE}

This report was prepared as an account of work sponsored by the United States Government. Neither the United States nor the United States Department of Energy, nor any of their employees, nor any of their contractors, subcontractors, or their employees, makes any warranty, expressed or implied, or assumes any legal liability or responsibility for the accuracy, completeness or usefulness of any information, apparatus, product or process disclosed, or represents that its use would not infringe privately owned rights.

\section{Printed in the United States of America \\ Available from: \\ National Technical Information Service \\ U.S. Department of Commerce \\ 5285 Port Royal Road \\ Springfield, VA 22161}

\section{Price: Microfiche A01}

Printed Copy A03

Codes are used for pricing all publications. The code is determined by the number of pages in the publication. Information pertaining to the pricing codes can be found in the current issue of the following publications, which are generally available in most libraries: Energy Research Abstracts, (ERA); Government Reports Announcements and index (GRA and I); Scientific and Technical Abstract Reports (STAR); and publication, NTIS-PR-360 available from NTIS at the above address. 


\section{PREFACE}

This report documents work performed by the Solar Energy Research Institute (SERI) Resource Assessment and Instrumentation Branch for the Department of Energy under Task No. 3414.10. It presents a new simple model for direct and diffuse spectral irradiance on horizontal and tilted surfaces at the earth's surface for clear days.

Approved for

SOLAR ENERGY RESEARCH INSTITUTE

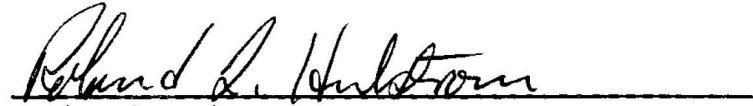

Roland Hulstrom, Manager

Resource Assessment and Instrumentation

Branch

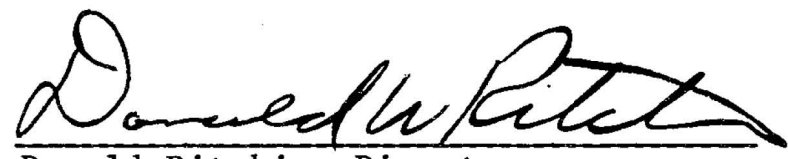

Donald Ritchie, Director

Solar Electric Research Division 


\section{SUMMARY}

\section{Objective}

To present a new, simple model for direct and diffuse spectral irradiance on horfzontal and tilted surfaces at the earth's surface for clear days.

\section{Discussion}

In a previous report (SERI/TR-215-1781), we described a simple model for calculating direct normal and diffuse horizontal spectral irradiance for clear days. In this report, we present a new, simple model that incorporates improvements to the simple model approach and an algorithm for calculating spectral irradiance on tilted surfaces. The goal is to provide researchers with the capability to calculate spectral irradiance for different atmospheric conditions and different collector configurations/orientations using microcomputers.

\section{Conclusions}

A new, simple, spectral irradiance model has been formulated that produces terrestrial spectra between 0.3 and $4.0 \mathrm{~m}$ with a resolution of approximately $10 \mathrm{~nm}$. Inputs to the model include the solar zenith angle, the collector tilt angle, atmospheric turbidity, the amount of precipitable water vapor and ozone, surface pressure, and ground albedo. 


\section{TABLE OF CONTENTS}

Page

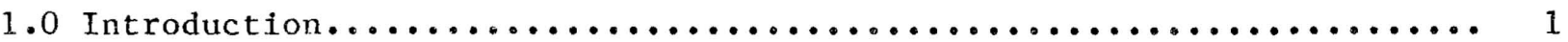

2.0 Direct Normal Irradiance............................ 2

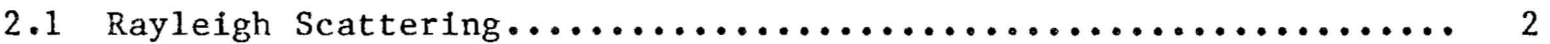

2.2 Aerosol Scattering and Absorption...................... 4

2.3 Water Vapor Absorption................................. 4

2.4 ozone and Uniformly Mixed Gas Absorption.................. 5

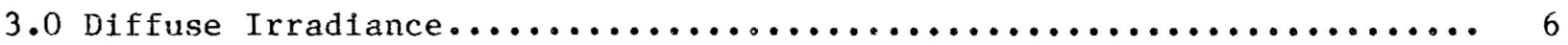

3.1 Diffuse Irradiance on a Horizontal Surface............... 6

3.2 Diffuse Irradiance on Inclined Surfaces................... 9

4.0 Comparisons of the New Simple Model with Rigorous Models

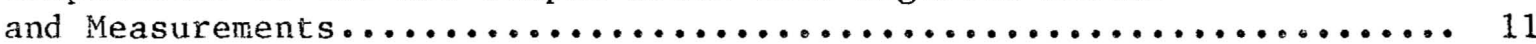

4.1 Comparison with Dave Rayleigh Scattering Data............. 11

4.2 Comparisons with BRITE Code Results....................... 11

4.3 Comparisons with Measured Data........................ 14

5.0 Examples of the Application of the New Simple Spectral Mode1........ 20

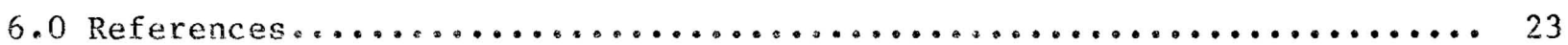

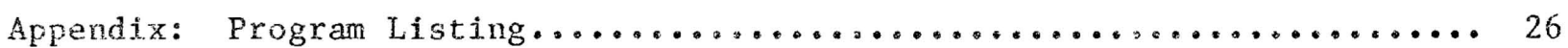




\section{LIST OF FIGURES}

Page

4-1 Comparison of Global Irradiance Calculated Using the SPCTRAL2 and BRITE codes for $\tau_{a}(0.5 \mu \mathrm{m})=0.10, \mathrm{Z}=0^{\circ}$, and Ti1t $=0^{\circ} \ldots \ldots \ldots 12$

4-2 Comparison of Global Irradiance Calculated Using the SPCTRAL2 and BRITE Codes for $\tau_{a}(0.5 \mathrm{~m})=0.51, Z=80^{\circ}$, and Tilt $=0^{\circ} \ldots \ldots 13$

4-3 Comparison of Global Irradiance Calculated Using the SPCTRAL2 and and BRITE Codes for $\tau_{a}(0.5 \mu \mathrm{m})=0.27, Z=48.19^{\circ}$, and Tilt $=37^{\circ} \ldots 13$

4-4 Comparison of Global Irradiance Calculated Using the SPCTRAL2 and BRITE Codes for $\tau_{a}(0.5 \mu \mathrm{m})=0.27, \mathrm{Z}=37^{\circ}$, and $\mathrm{Tilt}=60^{\circ} \ldots \ldots \ldots \ldots 14$

4-5 Turbidity at $0.5 \mathrm{\mu m}$ vs. Time of Day on 5 August 1981 , Golden, Co..... 15

4-6 Precipitable Water Vapor vs. Time of Day on 5 August 1981, Golden C0........................................ 15

4-7 Comparison between Global Horizontal Irradiance Measured on 5 August 1981, Golden, CO, and Modeled Data Using SPCTRAL2........ 17

4-8 Comparison between Global Horizontal Irradiance Measured on 19 August 1981, Golden, CO, and Modeled Data Using SPCTRAL2........ 17

4-9 Comparison between Direct Normal Irradiance Measured on 19 August 1981, Golden, CO, and Modeled Data Using SPCTRAL2........ 18

4-10 Comparison between Global Radiation on a South-Facing Surface Tilted $40^{\circ}$, Measured on 19 August 1981 , Golden, CO, and Modeled Data Using SPCTRAL2 (o on the graph) $\ldots \ldots \ldots \ldots \ldots \ldots \ldots \ldots \ldots$

4-11 Comparison Between Global Horizontal Irradiance Measured on 18 August 1981, Golden, CO, and Modeled Data Using SPCTRAL2........ 19

5-1 Global Irradiance on a South-Facing Surface Tilted $37^{\circ}$ for the Equinoxes (days 80 and 266) and for the Summer and winter

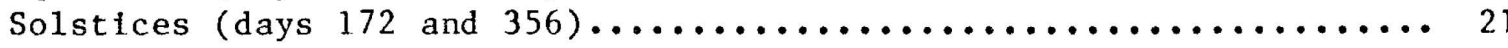

5-2 Photon Flux Density per Wavelength Interval Correspondins, 10 Global Irradtance Shown in Flgure 5-1 (diay $8(1) \ldots \ldots \ldots \ldots \ldots$

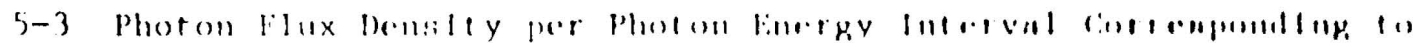

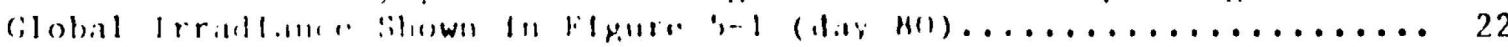




\section{LIST OF TABLES}

Page

2-1 The Neckel and Labs Revised Extraterrestrial Spectrum and Atmospheric Absorption Coefficients at 122 Wavelengths............

3-1 Diffuse Irradiance $\left(\mathrm{W} \mathrm{m}^{-2} \mu^{-1}\right)$ at Selected Wavelengths Calculated Using the BRITE Code, the Justus and Paris Code, and the Modified Justus and Paris Code...................... 8

4-1 Direct Normal Spectral Irradiance Comparison of Dave Results with SPCTRAL2 Results for a Rayleigh Atmosphere with Molecular Absorption....................................... 11

4-2 Diffuse Horizontal Spectral Irradiance Comparison of Dave Results with SPCTRAL2 Results for a Rayleigh Atmosphere with Molecular Absorption.................................

4-3 Meteorological and Geometrical Parameters on 19 August 1981

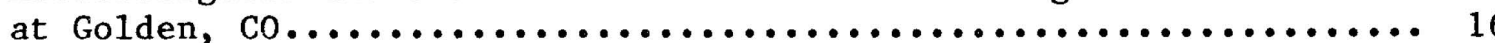




\section{SECTION 1.0}

\section{INTRODUCTION}

In previous work [1], we presented a simple model to calculate direct normal and diffuse horizontal spectral irradiance at the earth's surface for clear days. In this report, we present a new simple model that incorporates improvements in methodology as well as an algorithm to produce spectra for tilted surfaces. The goal of this work is to give researchers the capability to produce accurate terrestrial spectra using only a microcomputer.

The first model [1] was based on models developed by Leckner [2] and Brine and Iqbal [3]. Since that work was completed, Justus and Paris [4] have made improvements to the simple model approach. In the model presented here, we refined the Justus and Paris model and extended it to calculate spectra for tilted surfaces using methods developed by Hay and Davies [5]. Refinements to the Justus and Paris model were based on comparisons with results of rigorous radiative transfer codes and with measured spectra.

The new simple model and results are presented in the sections that follow. Sections 2.0 and 3.0 describe methods for calculating direct normal and diffuse spectral irradiance, respectively. Section 4.0 gives comparisons of the simple model results with rigorous model results and measurements. Examples of the application of the new model are given in Section 5.0 . 


\section{SECTION 2.0}

\section{DIRECT NORMAL IRRADIANCE}

Minor modifications have been made to the methods we reported in [1] for calculating direct normal irradiance. The changes include the addition of an earth-sun distance factor, the use of Leckner's water vapor transmittance expression [2] with some modification of Leckner's absorption coefficients, and the use of Robinson's ozone mass expression as given by Iqbal [6]. These changes and other minor adjustments are described in this section.

The direct irradiance on a surface normal to the direction of the sun at ground level for wavelength $\lambda$ is given by

$$
\mathrm{I}_{\mathrm{d} \lambda}=\mathrm{H}_{\mathrm{o} \lambda} \mathrm{D} \mathrm{T}_{\mathrm{r} \lambda} \mathrm{T}_{\mathrm{a} \lambda} \mathrm{T}_{\mathrm{w} \lambda} \mathrm{T}_{\mathrm{o} \lambda} \mathrm{T}_{\mathrm{u} \lambda}
$$

The parameter $\mathrm{H}_{\mathrm{O} \lambda}$ is the extraterrestrial irradiance at the mean earth-sun distance for wavelength $\lambda$; $D$ is the correction factor for the earth-sun distance; and $\mathrm{T}_{\mathrm{r} \lambda}, \mathrm{T}_{\mathrm{a} \lambda}, \mathrm{T}_{\mathrm{w} \lambda}, \mathrm{T}_{\mathrm{o} \lambda}$, and $\mathrm{T}_{\mathrm{u} \lambda}$ are the transmittance functions of the atmosphere at wavelength $\lambda$ for molecular (Rayleigh) scattering, aerosol attenuation, water vapor absorption, ozone absorption, and uniformly mixed gas absorption, respectively. The direct irradiance on a horizontal surface is obtained by multiplying Eq. 2-1 by $\cos \mathrm{Z}$, where $\mathrm{Z}$ is the solar zenith angle.

The extraterrestrial spectral irradiance used here was obtained from Frölich and Wehrli [7] of the World Radiation Center. A major segment of this spectrum that is of interest here was taken from the revised Neckel and Labs [8] spectrum. A 10-nm-resolution version of this spectrum is shown in Table 2-1 for the 122 wavelengths used in this mode1.

The earth-sun distance factor as given by Spencer [9] is

$$
\begin{aligned}
\mathrm{D}= & 1.00011+0.034221 \cos \psi+0.00128 \sin \psi \\
& +0.000719 \cos 2 \psi+0.000077 \sin 2 \psi .
\end{aligned}
$$

The day angle $\psi$ in radians is represented by

$$
\phi=2 \pi(d-1) / 365,
$$

where $d$ is the day number of a year $(1-365)$.

\subsection{RAYLEIGH SCATTERING}

The expression that we use for the atmospheric transmittance after Rayleigh scattering was taken from Kneizys et al. [10] and is

$$
\mathrm{T}_{\mathrm{r} \lambda}=\operatorname{EXP}\left\{-\mathrm{M}^{1} /\left[\lambda^{4}\left(115.6406-1.335 / \lambda^{2}\right)\right]\right\},
$$

where $M^{\prime}$ is the pressure-corrected air mass. The relative air mass as given by Kasten [11] is 
Table 2-1. The Neckel and Labs Revised Extraterrestrial Spectrum and Atmospheric Absorption Coefficients at 122 Wavelengths

\begin{tabular}{|c|c|c|c|c|c|c|c|c|c|}
\hline $\begin{array}{l}\text { Wavelength } \\
\qquad(\mu \pi)\end{array}$ & $\begin{array}{c}\text { Extraterrestrial } \\
\text { Spectrup } \\
\left(W^{-2} m^{-1}\right)\end{array}$ & ${ }^{a} w \lambda$ & $a_{o \lambda}$ & $a_{u \lambda}$ & $\begin{array}{l}\text { Wavelength } \\
(\mu \mathrm{m})\end{array}$ & $\begin{array}{c}\text { Extraterrestrial } \\
\text { Spectrum } \\
\left(\mathrm{wm}^{-2} \mathrm{~mm}^{-1}\right)\end{array}$ & $a_{w \lambda}$ & $a_{0 \lambda}$ & $a_{u \lambda}$ \\
\hline 0.300 & 535.9 & 0.0 & 10.0 & 0.0 & 0.980 & 767.0 & 1.48 & 0.0 & 0.0 \\
\hline 0.305 & 558.3 & 0.0 & 4.80 & 0.0 & 0.9935 & 757.6 & 0.1 & 0.0 & 0.0 \\
\hline 0.310 & 622.0 & 0.0 & 2.70 & 0.0 & 1.04 & 688.1 & 0.00001 & 0.0 & 0.0 \\
\hline 0.315 & 692.7 & 0.0 & 1.35 & 0.0 & 1.07 & 640.7 & 0.001 & 0.0 & 0.0 \\
\hline 0.320 & 715.1 & 0.0 & 0.800 & 0.0 & 1.10 & 606.2 & 3.2 & 0.0 & 0.0 \\
\hline 0.325 & 832.9 & 0.0 & 0.380 & 0.0 & 1.12 & 585.9 & 115.0 & 0.0 & 0.0 \\
\hline 0.335 & 931.9 & 0.0 & 0.075 & 0.0 & 1.145 & 564.1 & 75.0 & 0.0 & 0.0 \\
\hline 0.340 & 900.6 & 0.0 & 0.040 & 0.0 & 1.161 & 544.2 & 10.0 & 0.0 & 0.0 \\
\hline 0.345 & 911.3 & 0.0 & 0.019 & 0.0 & 1.17 & 533.4 & 5.0 & 0.0 & 0.0 \\
\hline 0.350 & 975.5 & 0.0 & 0.007 & 0.0 & 1.20 & 501.6 & 2.0 & 0.0 & 0.0 \\
\hline 0.360 & 975.9 & 0.0 & 0.0 & 0.0 & 1.24 & 477.5 & 0.002 & 0.0 & 0.05 \\
\hline 0.370 & 1119.9 & 0.0 & 0.0 & 0.0 & 1.27 & 422.7 & 0.002 & 0.0 & 0.30 \\
\hline 0.380 & 1103.8 & 0.0 & 0.0 & 0.0 & 1.29 & 440.0 & 0.1 & 0.0 & 0.02 \\
\hline 0.390 & 1033.8 & 0.0 & 0.0 & 0.0 & 1.32 & 416.8 & 4.0 & 0.0 & 0.0002 \\
\hline 0.400 & 1479.1 & 0.0 & 0.0 & 0.0 & 1.35 & 391.4 & 200.0 & 0.0 & 0.00011 \\
\hline 0.410 & 1701.3 & 0.0 & 0.0 & 0.0 & 1.395 & 358.9 & 1000.0 & 0.0 & 0.00001 \\
\hline 0.430 & 1587.2 & 0.0 & 0.0 & 0.0 & 1.4625 & 317.5 & 80.0 & 0.0 & 0.011 \\
\hline 0.440 & 1837.0 & 0.0 & 0.0 & 0.0 & 1.477 & 307.3 & 80.0 & 0.0 & 0.005 \\
\hline 0.450 & 2005.0 & 0.0 & 0.003 & 0.0 & 1.497 & 300.4 & 12.0 & 0.0 & 0.0006 \\
\hline 0.460 & 2043.0 & 0.0 & 0.006 & 0.0 & 1.520 & 292.8 & 0.16 & 0.0 & 0.0 \\
\hline 0.470 & 1987.0 & 0.0 & 0.009 & 0.0 & 1.539 & 275.5 & 0.002 & 0.0 & 0.005 \\
\hline 0.480 & 2027.0 & 0.0 & 0.014 & 0.0 & 1.558 & 272.1 & 0.0005 & 0.0 & 0.13 \\
\hline 0.490 & 1896.0 & 0.0 & 0.021 & 0.0 & 1.578 & 259.3 & 0.0001 & 0.0 & 0.04 \\
\hline 0.500 & 1909.0 & 0.0 & 0.030 & 0.0 & 1.592 & 246.9 & 0.00001 & 0.0 & 0.06 \\
\hline 0.510 & 1927.0 & 0.0 & 0.040 & 0.0 & 1.610 & 244.0 & 0.0001 & 0.0 & 0.13 \\
\hline 0.520 & 1831.0 & 0.0 & 0.048 & 0.0 & 1.630 & 243.5 & 0.001 & 0.0 & 0.001 \\
\hline 0.530 & 1891.0 & 0.0 & 0.063 & 0.0 & 1.646 & 234.8 & 0.01 & 0.0 & 0.0014 \\
\hline 0.540 & 1898.0 & 0.0 & 0.075 & 0.0 & 1.678 & 220.5 & 0.036 & 0.0 & 0.0001 \\
\hline 0.550 & 1892.0 & 0.0 & 0.085 & 0.0 & 1.740 & 190.8 & 1.1 & 0.0 & 0.00001 \\
\hline 0.570 & 1840.0 & 0.0 & 0.120 & 0.0 & 1.80 & 171.1 & 130.0 & 0.0 & 0.00001 \\
\hline 0.593 & 1768.0 & 0.075 & 0.119 & 0.0 & 1.860 & 144.5 & 1000.0 & 0.0 & 0.0001 \\
\hline 0.610 & 1728.0 & 0.0 & 0.120 & 0.0 & 1.920 & 135.7 & 500.0 & 0.0 & 0.001 \\
\hline 0.630 & 1658.0 & 0.0 & 0.090 & 0.0 & 1.960 & 123.0 & 100.0 & 0.0 & 4.3 \\
\hline 0.656 & 1524.0 & 0.0 & 0.065 & 0.0 & 1.985 & 123.8 & 4.0 & 0.0 & 0.20 \\
\hline 0.6676 & 1531.0 & 0.0 & 0.051 & 0.0 & 2.005 & 113.0 & 2.9 & 0.0 & 21.0 \\
\hline 0.690 & 1420.0 & 0.016 & 0.028 & 0.15 & 2.035 & 108.5 & 1.0 & 0.0 & 0.13 \\
\hline 0.740 & 1298.0 & 0.061 & 0.010 & 0.0 & 2.198 & 74.6 & 0.33 & 0.0 & 0.00038 \\
\hline 0.7525 & 1269.0 & 0.0008 & 0.008 & 0.0 & 2.270 & 68.3 & 0.50 & 0.0 & 0.001 \\
\hline 0.7575 & 1245.0 & 0.0001 & 0.007 & 0.0 & 2.360 & 63.8 & 4.0 & 0.0 & 0.0005 \\
\hline 0.7625 & 1223.0 & 0.00001 & 0.006 & 4.0 & 2.450 & 49.5 & 80.0 & 0.0 & 0.00015 \\
\hline 0.7675 & 1205.0 & 0.00001 & 0.005 & 0.35 & 2.5 & 48.5 & 310.0 & 0.0 & 0.00014 \\
\hline 0.780 & 1183.0 & 0.0006 & 0.0 & 0.0 & 2.6 & 38.6 & 5000.0 & 0.0 & 0.00066 \\
\hline 0.800 & 1148.0 & 0.0360 & 0.0 & 0.0 & 2.7 & 36.6 & 22000.0 & 0.0 & 100.0 \\
\hline 0.816 & 1091.0 & 1.60 & 0.0 & 0.0 & 2.8 & 32.0 & 8000.0 & 0.0 & 150.0 \\
\hline 0.8237 & 1062.0 & 2.5 & 0.0 & 0.0 & 2.9 & 28.1 & 650.0 & 0.0 & 0.13 \\
\hline 0.8315 & 1038.0 & 0.500 & 0.0 & 0.0 & 3.0 & 24.8 & 240.0 & 0.0 & 0.0095 \\
\hline 0.840 & 1022.0 & 0.155 & 0.0 & 0.0 & 3.1 & 22.1 & 230.0 & 0.0 & 0.001 \\
\hline 0.860 & 998.7 & 0.00001 & 0.0 & 0.0 & 3.2 & 19.6 & 100.0 & 0.0 & 0.8 \\
\hline 0.880 & 947.2 & 0.0026 & 0.0 & 0.0 & 3.3 & 17.5 & 120.0 & 0.0 & 1.9 \\
\hline 0.905 & 893.2 & 7.0 & 0.0 & 0.0 & 3.4 & 15.7 & 19.5 & 0.0 & 1.3 \\
\hline 0.915 & 868.2 & 5.0 & 0.0 & 0.0 & 3.5 & 14.1 & 3.6 & 0.0 & 0.075 \\
\hline 0.925 & 829.7 & 5.0 & 0.0 & 0.0 & 3.6 & 12.7 & 3.1 & 0.0 & 0.01 \\
\hline 0.930 & 830.3 & 27.0 & 0.0 & 0.0 & 3.7 & 11.5 & 2.5 & 0.0 & 0.00195 \\
\hline 0.937 & 814.0 & 55.0 & 0.0 & 0.0 & 3.8 & 10.4 & 1.4 & 0.0 & 0.004 \\
\hline 0.948 & 786.9 & 45.0 & 0.0 & 0.0 & 3.9 & 9.5 & 0.17 & 0.0 & 0.29 \\
\hline 0.965 & 768.3 & 4.0 & 0.0 & 0.0 & 4.0 & 8.6 & 0.0045 & 0.0 & 0.025 \\
\hline
\end{tabular}




$$
M=\left[\cos Z+0.15(93.885-z)^{-1.253}\right]^{-1},
$$

where $\mathrm{Z}$ is the apparent solar zenith angle. The pressure-corrected air mass is $M^{\prime}=M P / P_{0}$, where $P_{0}=1013 \mathrm{mb}$ and $P$ is measured surface pressure in mb.

\subsection{AEROSOL SCATTERING AND ABSORPTION}

In our previous work [1], we used an aerosol transmittance expression of the form

$$
\mathrm{T}_{\mathrm{a} \lambda}=\operatorname{EXP}\left(-\beta_{\mathrm{n} \lambda}{ }^{-\alpha} \mathrm{n}_{\mathrm{M}}\right)
$$

Values for $\beta$ and $\alpha$ were derived using a rural aerosol model [12]. Two $\alpha$ values were used for this aerosol model: $\alpha_{1}=1.0274$ for wavelengths $<0.5 \mu \mathrm{m}$, and $\alpha_{2}=1.2060$ for wavelengths $\geqslant 0.5 \mu \mathrm{m}$. The value of $\beta_{n}$ was chosen appropriately for each wavelength interval to produce accurate turbidity values (aerosol optical depth in a vertical path) at $0.5 \mu \mathrm{m}$ wavelength. The turbidity in Eq. 2-6 is represented by the Angstrom formula [13], namely,

$$
\tau_{a \lambda}=\beta_{n} \lambda^{-\alpha} \text {. }
$$

For some types of aerosols, it may be important to separate the aerosol extinction into two or more segments, as we have done here for the rural aerosol model. The form of $\mathrm{Eq} \cdot 2-6$ allows the turbidity versus the wavelengths on a log-log plot to be nonlinear, which often occurs in the real atmosphere, as shown by King and Herman [14]. However, for the rural aerosol model [12], this does not appear to significantly improve the accuracy of the modeled results since the function is approximately linear. Also, the approximate nature of this simple model approach sometimes masks the effect of refinements such as this. When a single value of $\alpha$ is used to represent the rural aerosol model, the value should be $\alpha=1.140$.

\subsection{WATER VAPOR ABSORPTION}

We adopted the water vapor transmittance expression of Leckner [2], which has the form

$$
\mathrm{T}_{\mathrm{w} \lambda}=\operatorname{EXP}\left[-0.2385 \mathrm{a}_{\mathrm{w} \lambda} \mathrm{WM} /\left(1+20.07 \mathrm{a}_{\mathrm{w} \lambda} \mathrm{WM}\right)^{0.45}\right],
$$

where $W$ is the precipitable water vapor $(\mathrm{cm})$ in a vertical path and $a_{W \lambda}$ is the water vapor absorption coefficient as a function of wavelength. The water vapor amount $W$ is not temperature- or pressure-corrected because this has been accounted for in the form of Eq. 2-8. We modified Leckner's values of $a_{w} \lambda$ somewhat and added several values to achieve better agreement with experimental data. The coefficients are given in Table 2-1. In our previous model, we used a misprinted version of Leckner's expression, which necessitated modifications to the expression and to the absorption coefficients to obtain reasonable agreement with rigorous model results. The correct form, shown in Eq. 2-8, gives better results. 


\subsection{OZONE AND UNIFORMLY MIXED GAS ABSORPTION}

Leckner's ozone transmittance equation [2] was used, which is

$$
\mathrm{T}_{\mathrm{o} \lambda}=\operatorname{EXP}\left(-\mathrm{a}_{\mathrm{o} \lambda} \mathrm{O}_{3} \mathrm{M}_{\mathrm{o}}\right),
$$

where $a_{0} \lambda$ is the ozone absorption coefficient, $0_{3}$ is the ozone amount (atm$\mathrm{cm})$, and $\mathrm{M}_{0}$ is the ozone mass. We used Leckner's ozone absorption coefficients shown in Table 2-1. The ozone mass expression of Robinson as given by Iqbal [6] has been adopted. The ozone mass is given by

$$
M_{0}=\left(1+h_{o} / 6370\right) /\left(\cos ^{2} z+2 h_{o} / 6370\right)^{0.5} \text {. }
$$

The parameter $h_{0}$ is the height of maximum ozone concentration, which is approximately $22 \mathrm{~km}$. The ozone height varies with latitude and time of year. If one does not have ozone measurements available, the ozone amount can be estimated using the expression of Van Heuklon [15]. Since the total ozone amount is an approximation, using $\mathrm{O}_{3} \mathrm{M}_{0}$ rather than $\mathrm{O}_{3} \mathrm{M}$ may not be an improvement.

Leckner's expression for uniformly mixed gas transmittance is used, and it is expressed as

$$
\mathrm{T}_{\mathbf{u} \lambda}=\operatorname{EXP}\left[-1.41 \mathrm{a}_{\mathbf{u} \lambda} \mathrm{M}^{\prime} /\left(1+118.93 \mathrm{a}_{\mathbf{u} \lambda} \mathrm{M}^{\prime}\right)^{0.45}\right],
$$

where $a_{u \lambda}$ is the combination of an absorption coefficient and gaseous amount. 'We used Leckner's values of $a_{u} \lambda$ shown in Table 2-1 with a few additions and modifications. Final adjustments were made in the gaseous absorption coefficients by comparing the modeled data with measured data, as described in Section 4.0. 


\section{SECTION 3.0}

\section{DIFFUSE IRRADIANCE}

The diffuse irradiance is difficult to determine accurately with the simple parameterization methods that were used to calculate direct normal irradiance in the previous section. We used tabulated correction factors in our previous research [1] to make the simple formulation for the diffuse irradiance of Brine and Iqbal [3] match the results from a rigorous radiative transfer code. Justus and Paris [4] changed the diffuse formulation somewhat and obtained reasonable agreement with rigorous code results without using tabulated correction factors. We examined this new formulation and made some minor adjustments which we believe improve its accuracy. The correction table approach is still valid and may be the most accurate approach; however, this new formulation is more flexible and is easier to implement.

In addition, we examined different simple formulations for producing spectra on inclined surfaces. We obtained reasonable success with this effort and report our results here.

\subsection{DIFFUSE IRRADIANCE ON A HORIZONTAL SURFACE}

The diffuse irradiance on a horizontal surface is divided into three components: (1) the Rayleigh scattering component $I_{\mathbf{r} \lambda}$, (2) the aerosol scattering component $I_{a \lambda}$, and (3) the component that accounts for multiple reflection of irradiance between the ground and the air $I_{g} \lambda^{*}$ The total scattered irradiance $I_{s} \lambda$ is then given by the sum

$$
I_{s \lambda}=I_{r \lambda}+I_{a \lambda}+I_{g \lambda}
$$

If we consider the Rayleigh and aerosol scattering to be independent of each other, the following expressions would be approximately correct:

$$
\begin{gathered}
\mathrm{I}_{\mathrm{r} \lambda}=\mathrm{H}_{\mathrm{o} \lambda} \mathrm{D} \cos \mathrm{Z} \mathrm{T}_{\mathrm{o} \lambda} \mathrm{T}_{\mathrm{u} \lambda} \mathrm{T}_{\mathrm{w} \lambda} \mathrm{T}_{\mathrm{a} \lambda}\left(1-\mathrm{T}_{\mathrm{r} \lambda}\right) 0.5 \\
\mathrm{I}_{\mathrm{a} \lambda}=\mathrm{H}_{\mathrm{o} \lambda} \mathrm{D} \cos \mathrm{Z} \mathrm{T}_{\mathrm{o} \lambda} \mathrm{T}_{\mathrm{u} \lambda} \mathrm{T}_{\mathrm{w} \lambda} \mathrm{T}_{\mathrm{r} \lambda} \mathrm{T}_{\mathrm{aa} \lambda}\left(1-\mathrm{T}_{\mathrm{as} \lambda}\right) \mathrm{F}_{\mathrm{s}} \cdot
\end{gathered}
$$

In these formulas, we have assumed that half of the Rayleigh scatter is downward regardless of the zenith angle of the sun, and that a fraction $F_{s}$ of the aerosol scatter is downward and can be a function of the solar zenith angle. The transmittance terms $\mathrm{T}_{\text {aa } \lambda}$ and $\mathrm{T}_{\text {as } \lambda}$ are for aerosol absorption and aerosol scattering, respectively. In our previous model [1], we used the assumption of independent scattering, and $\mathrm{Eq}$. 3-3 has the following form:

$$
\mathrm{I}_{\mathrm{a} \lambda}=\mathrm{H}_{\mathrm{o} \lambda} \mathrm{D} \cos \mathrm{Z} \mathrm{T}_{\mathrm{o} \lambda} \mathrm{T}_{\mathrm{u} \lambda} \mathrm{T}_{\mathrm{w} \lambda} \mathrm{T}_{\mathrm{r} \lambda}\left(1-\mathrm{T}_{\mathrm{a} \lambda}\right) \omega_{\mathrm{o}} \mathrm{F}_{\mathrm{a}} \text {, }
$$

where $\omega_{0}$ is the aerosol single scattering albedo at one wavelength and $\mathrm{F}_{a}$ is the aerosol forward scattering fraction which is independent of the sun position. We found that this formula significantly underestimated the scattered irradiance for $\mathrm{Z}>60^{\circ}$. 
In the new simple spectral model reported here, we used modifications of the Justus and Paris expressions [4] for diffuse irradiance. Comparisons with diffuse irradiance calculated using a rigorous radiative transfer code (BRITE) [16] indicated a tendency for the Justus and Paris model to overestimate the energy in the UV and visible portions of the spectrum. This overestimation increased as the turbidity and air mass increased. By slightly modifying the expression, we were able to obtain closer agreement with BRITE results. Table 3-1 gives examples of the results of these comparisons. The modified expressions are

$$
\begin{aligned}
& \mathrm{I}_{\mathrm{r} \lambda}=\mathrm{H}_{\mathrm{o} \lambda} \mathrm{D} \cos \mathrm{Z} \mathrm{T}_{\mathrm{o} \lambda} \mathrm{T}_{\mathrm{u} \lambda} \mathrm{T}_{\mathrm{w} \lambda} \mathrm{T}_{\mathrm{aa} \lambda}\left(1-\mathrm{T}_{\mathrm{r} \lambda}{ }^{0.95}\right) 0.5 \mathrm{C}_{\mathrm{s}} \\
& \mathrm{I}_{\mathrm{a} \lambda}=\mathrm{H}_{\mathrm{o} \lambda} \mathrm{D} \cos \mathrm{Z} \mathrm{T}_{\mathrm{o} \lambda} \mathrm{T}_{\mathrm{u} \lambda} \mathrm{T}_{\mathrm{w} \lambda} \mathrm{T}_{\mathrm{aa} \lambda} \mathrm{T}_{\mathrm{r} \lambda}{ }^{1.5}\left(1-\mathrm{T}_{\mathrm{as}} \lambda\right) \mathrm{F}_{\mathrm{s}} \mathrm{C}_{\mathrm{s}} \\
& I_{g \lambda}=\left(I_{d \lambda} \cos Z+I_{r \lambda}+I_{a \lambda}\right) r_{s} r_{g} C_{s} /\left(1-r_{s} \lambda r_{g}\right) \\
& \mathrm{r}_{\mathbf{s} \lambda}=\mathrm{T}_{\mathrm{o} \lambda}^{\prime} \mathrm{T}_{\mathbf{w} \lambda}^{\prime} \mathrm{T}_{\mathrm{a} a \lambda}^{\prime}\left[0.5\left(1-\mathrm{T}_{\mathbf{r} \lambda}^{\prime}\right)+\left(1-\mathrm{F}_{\mathbf{s}}^{\prime}\right) \mathrm{T}_{\mathbf{r} \lambda}^{\prime}\left(1-\mathrm{T}_{\mathrm{as}}^{\prime} \lambda\right)\right] \\
& \mathrm{T}_{\mathrm{as} \lambda}=\operatorname{EXP}\left(-\omega_{\lambda} \tau_{\mathrm{a} \lambda} \mathrm{M}\right) \\
& \mathrm{T}_{\mathrm{aa} \lambda}=\operatorname{EXP}\left[-\left(1-\omega_{\lambda}\right) \tau_{\mathrm{a} \lambda} \mathrm{M}\right] \\
& F_{S}=1-0.5 \mathrm{EXP}[(\mathrm{AFS}+\mathrm{BFS} \cos \mathrm{Z}) \cos \mathrm{Z}] \\
& \mathrm{AFS}=\operatorname{ALG}[1.459+\operatorname{ALG}(0.1595+\operatorname{ALG} 0.4129)] \\
& \mathrm{BFS}=\mathrm{ALG}[0.0783+\mathrm{ALG}(-0.3824-\mathrm{ALG} 0.5874)] \\
& \mathrm{ALG}=\ln (1-\langle\cos \theta\rangle) \\
& \mathrm{F}_{\mathbf{S}}^{\prime}=1-0.5 \mathrm{EXP}[(\mathrm{AFS}+\mathrm{BFS} / 1.8) / 1.8] \\
& \omega_{\lambda}=\omega_{0.4} \operatorname{EXP}\left\{-\omega^{\prime}[\ln (\lambda / 0.4)]^{2}\right\} \\
& c_{s}=\begin{array}{cl}
(\lambda+0.55)^{1.8} & \text { for } \lambda \leqslant 0.45 \mathrm{\mu m} \\
1.0 & \text { for } \lambda>0.45 \mathrm{~m}
\end{array} .
\end{aligned}
$$

The parameter $r_{g}$ is the ground albedo as a function of wavelength, $r_{s} \lambda$ is the sky reflectivity, and the primed transmittance terms are the regular atmospheric transmittance terms evaluated at $M=1.8 . \omega_{\lambda}$ is the aerosol single scattering albedo as a function of wavelength, $\omega_{0}$ is the single scattering albedo at $0.4 \mathrm{~m}$ wavelength, $\omega^{\prime}$ is the wavelength iariation factor, and $\langle\cos \theta\rangle$ is the aerosol asymmetry factor. For the rural aerosol model, $\omega_{0.4}=0.945, \omega^{\gamma}=0.095$, and $\langle\cos \theta\rangle=0.65$. The equations for $T_{\text {as }} \lambda$ and $T_{\text {aa }} \lambda$ ensure that $T_{a \lambda}$ is equal to $T_{a s} \lambda \cdot T_{a a}$ and that the wavelength-dependent single scattering albedo is correctly defined by $\omega_{\lambda}=s_{a} \lambda /\left(s_{a} \lambda+k_{a}\right)$. The parameters $s_{a \lambda}$ and $k_{a} \lambda$ are the aerosol scattering and absorption coefficients, respectively. In a homogeneous medium, the optical depth is related to these coefficients by $\tau_{a \lambda}=\left(s_{a \lambda}+k_{a \lambda}\right) L$, where $L$ is the path length in the medium. 
Table 3-1. Diffuse Irradiance $\left(\mathrm{W} \mathrm{m}^{-2} \mathrm{\mu m}^{-1}\right)$ at Selected Wavelengths Calculated Using the BRITE Code, the Justus and Paris Code, and the Modified Justus and Paris Code. (Model parameters for (a) and (b) are $\alpha=1.14$, ground albedo $=0.2, \mathrm{O}_{3}=0.344 \mathrm{~atm}-\mathrm{cm}$, and $\mathrm{H}_{2} \mathrm{O}=1.42 \mathrm{~cm}$.)

\begin{tabular}{|c|c|c|c|c|c|}
\hline$\lambda$ & BRITE (1) & $\begin{array}{l}\text { Justus/ } \\
\text { Paris (2) }\end{array}$ & $\begin{array}{c}\text { Modified } \\
\text { Justus/Paris (3) }\end{array}$ & $\begin{array}{l}\text { Ratio, } \\
2 / 1^{a}\end{array}$ & $\begin{array}{l}\text { Ratio, } \\
3 / 1 \mathrm{~b}\end{array}$ \\
\hline \multicolumn{6}{|c|}{ (a) $\tau=0.27, Z=60^{\circ}$} \\
\hline $\begin{array}{l}0.31 \\
0.35 \\
0.40 \\
0.45 \\
0.50 \\
0.55 \\
0.71 \\
0.78 \\
0.9935 \\
2.1\end{array}$ & $\begin{array}{c}11.9 \\
172.6 \\
307.2 \\
382.7 \\
306.6 \\
260.6 \\
173.6 \\
141.9 \\
51.9 \\
1.85\end{array}$ & $\begin{array}{r}25.5 \\
243.3 \\
343.5 \\
419.8 \\
351.8 \\
301.3 \\
169.7 \\
130.0 \\
60.4 \\
2.3\end{array}$ & $\begin{array}{r}17.7 \\
174.5 \\
268.5 \\
368.0 \\
317.0 \\
278.1 \\
163.9 \\
126.7 \\
59.8 \\
2.3\end{array}$ & $\begin{array}{l}2.14 \\
1.41 \\
1.12 \\
1.10 \\
1.15 \\
1.16 \\
0.98 \\
0.92 \\
1.16 \\
1.24\end{array}$ & $\begin{array}{l}1.49 \\
1.01 \\
0.87 \\
0.96 \\
1.03 \\
1.07 \\
0.94 \\
0.89 \\
1.15 \\
1.24\end{array}$ \\
\hline \multicolumn{6}{|c|}{ (b) $\tau=0.51, z=80^{\circ}$} \\
\hline $\begin{array}{l}0.31 \\
0.35 \\
0.40 \\
0.45 \\
0.50 \\
0.55 \\
0.78 \\
0.9935\end{array}$ & $\begin{array}{c}0.28 \\
37.9 \\
80.3 \\
125.2 \\
126.0 \\
115.0 \\
81.0 \\
44.6\end{array}$ & $\begin{array}{c}0.34 \\
71.2 \\
114.8 \\
160.8 \\
149.3 \\
135.0 \\
89.5 \\
48.2\end{array}$ & $\begin{array}{c}0.26 \\
56.8 \\
92.8 \\
133.6 \\
122.6 \\
113.3 \\
83.9 \\
47.0\end{array}$ & $\begin{array}{l}1.21 \\
1.88 \\
1.43 \\
1.28 \\
1.18 \\
1.17 \\
1.10 \\
1.08\end{array}$ & $\begin{array}{l}0.93 \\
1.50 \\
1.16 \\
1.07 \\
0.97 \\
0.99 \\
1.04 \\
1.05\end{array}$ \\
\hline
\end{tabular}

${ }^{a_{\text {Ratio }}}$ of Justus and Paris data (2) to BRITE data (1).

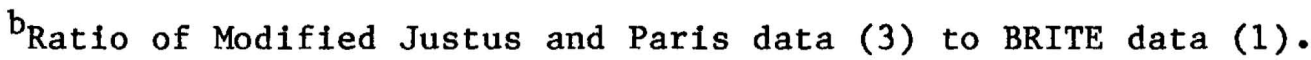

The only adjustments that we made to the Justus and Paris model [4] were to take $\mathrm{T}_{\mathrm{r} \lambda}$ to the 0.95 power instead of to the 1.0 power in Eq. 3-5, to take $\mathrm{T}_{\mathrm{r}} \lambda$ to the 1.5 power instead of to the 1.0 power in Eq. 3-6, and to multiply by $\mathrm{C}_{\mathrm{s}}$ in Eqs. 3-5, 3-6, and 3-7. As mentioned previously, we also changed several absorption coefficients.

It is important to note that the parameters used in the simple spectral model for the comparisons in Table 3-1 were selected to match the atmospheric conditions used in the BRITE code. This includes the use of the rural aerosol model and parameters that represent it. Since the rural aerosol model was used in a rigorous fashion in the BRITE code, our modifications to the Justus and Paris model are based on realistic aerosol data as well as other realistic atmospheric conditions. Some model comparisons could be misleading if sufficient attention is not given to the details of the parameters used. This could be the case for comparisons with the Dave aerosol mode1s (17). A constant complex index of refraction for all wavelengths is used in these 
models, which is not representative of real aerosols and has an effect on the single scattering albedo as a function of wavelength.

It should also be noted that $\omega_{\lambda}$ is difficult to determine and is quite variable in the real world. Justus [18] has derived an expression for $\omega_{\lambda}$ for the urban aerosol model as a function of relative humidity. This parameter affects only the diffuse component, so the global radiation at the ground should not be overly sensitive to the values used. This is not the case when the upwelling radiation at the top of the atmosphere is calculated as Justus and Paris did.

\subsection{DIFFUSE IRRADIANCE ON INCLINED SURFACES}

There have been several algorithms produced [5, 19-22] that convert the broadband global horizontal irradiance to the broadband global irradiance on a tilted surface. Most of these conversion algorithms require the direct normal and the diffuse on a horizontal surface as input. Several algorithms have been evaluated with measured data [23-26] in recent years. Some of them appear to be quite accurate for broadband applications for east-, west-, and south-facing surfaces. Perez et al. [26] found that the algorithms were somewhat inadequate for north-facing surfaces. This is partially because there is less irradiance on north-facing slopes.

We used three of these simple conversion algorithms to produce spectral irradiance on tilted surfaces by using the spectral direct and diffuse irradiance calculations of the previous section as inputs to the conversion algorithm. We obtained the best agreement with rigorous modeled data for clear-sky conditions using the Hay and Davies [5] algorithm. This was somewhat surprising because the way in which the algorithms were formulated would favor the Temps and Coulson [21] algorithms over the Hay and Davies [5] and Klucher [21] algorithms for clear-sky applications. The Hay and Davies algorithm is presented jn this section and the results of comparisons with rigorous code results and measured data are presented in the next sectione

The spectral global irradiance on an inclined surface is represented by

$$
\begin{aligned}
I_{\mathrm{T} \lambda}(t)= & I_{\mathrm{d} \lambda} \cos \theta+I_{\mathrm{s} \lambda}\left[\left(I_{\mathrm{d} \lambda} \cos \theta /\left(\mathrm{H}_{\mathrm{O}} \lambda \mathrm{D} \cos \mathrm{Z}\right)\right)\right. \\
& \left.+0.5(1+\cos t)\left(1-\mathrm{I}_{\mathrm{d} \lambda} /\left(\mathrm{H}_{\mathrm{O}} \lambda \mathrm{D}\right)\right)\right] \\
& +0.5 \mathrm{I}_{\mathrm{T} \lambda} \mathrm{r}_{\mathrm{g} \lambda}(1-\cos t),
\end{aligned}
$$

where $\theta$ is the angle of incidence of the direct beam on the tilted surface and $t$ is the tilt angle of the inclined surface. The tilt angle is zero for a horizontal surface and $90^{\circ}$ for a vertical surface. The following relationship holds for the spectral global irradiance on a horizontal surface:

$$
\mathrm{I}_{\mathrm{T} \lambda}=\mathrm{I}_{\mathrm{d} \lambda} \cos \mathrm{Z}+\mathrm{I}_{\mathrm{S} \lambda}
$$

The first term in Eq. 3-18 is the direct component on the inclined surface. The second term has two components: the first is the circumsolar or aureole and the second is a diffuse skylight component. The third term in Eq. 3-18 represents the isotropically reflected radiation from the ground. A component that is missing from this model is the horizon-brightening radiation. There 
are arguments that could be made as to why this algorithm should not be accurate, but the fact that it is reasonably accurate for the cases that we have checked cannot be ignored. It is somewhat surprising that a broadband model can be used for spectral data. 


\section{SECTION 4.0 \\ COMPARISONS OF THE NEW SIMPLE MODEL WITH RIGOROUS MODELS AND MEASUREMENTS}

Comparisons of the new, simple spectral model with results of rigorous radiative transfer codes and with measured data are given in this section. These comparisons give the reader some measure of the accuracy of the simple model.

\subsection{COMPARISON WITH DAVE RAYLEIGH SCATTERING DATA}

Dave [17] produced several data sets using the Spherical Harmonics method of solving the radiative transfer equation. One of the data sets was for a Rayleigh atmosphere (no aerosols) with molecular absorption. The atmospheric model that was used (the Midlatitude Summer model) contained $2.93 \mathrm{~cm}$ of precipitable water and $0.31 \mathrm{~atm}-\mathrm{cm}$ of ozone. A comparison of Dave's results with the results of the mode1 presented here (SPCTRAL2) is shown in Tables 4-1 and 4-2 at a few wavelengths throughout the spectrum. Table 4-1 compares the direct normal irradiance for three solar zenith angles, and Table 4-2 compares the diffuse irradiance for the same solar zenith angles. The direct normal irradiance was produced using Eq. 2-1 with $\mathrm{T}_{\mathrm{a} \lambda}=1.0$ and $\mathrm{D}=1.0$. The diffuse horizontal irradiance was found using $\mathrm{Eq} .3-5$ with $\mathrm{D}=1.0, \mathrm{~T}_{\mathrm{aa} \lambda}=1.0$, and $\mathrm{C}_{\mathrm{s}}=1.0$.

\subsection{COMPARISONS WITH BRITE CODE RESULTS}

Examples of comparisons between BRITE [16] code results and results of the SPCTRAL2 code are presented in Figures 4-1 through 4-4 for global irradiance. Figure $4-1$ is for a horizontal surface with zenith angle $(Z)=0.0^{\circ}$,

Table 4-1. Eirect Normal Spectral Irradiance Comparison of Dave Results with SPCTRAL2 Results for a Rayleigh Atmosphere with Molecular Abscrption $\left(\mathrm{O}_{3}=0.31\right.$ atm $\left.-\mathrm{cm}, \mathrm{H}_{2} \mathrm{C}=2.93 \mathrm{~cm}\right)$

\begin{tabular}{|c|c|c|c|c|c|c|}
\hline \multicolumn{3}{|c|}{$\mathrm{Z}=0^{\mathrm{O}}$} & \multicolumn{2}{|c|}{$Z=60^{\circ}$} & \multicolumn{2}{|c|}{$Z=80^{\circ}$} \\
\hline$\lambda(\mu \mathrm{m})$ & Dave & SPCTRAL2 & Dave & SPCTRAL2 & Dave & SPCTRAL2 \\
\hline 0.31 & 105.4 & 1.03 .0 & 16.1 & 15.8 & 0.01 & 0.0 \\
\hline 0.36 & 607.7 & 607.1 & 345.8 & 346.3 & 41.5 & 45.6 \\
\hline 0.415 & 1299.0 & 1298.0 & 951.0 & 951.7 & 294.5 & 310.2 \\
\hline 0.515 & 1591.0 & 1590.0 & 1381.0 & 1380.0 & 811.5 & 832.0 \\
\hline 0.615 & 1469.0 & 1469.0 & 1334.0 & 1334.0 & 926.7 & 953.7 \\
\hline 0.7035 & 1292.0 & 1291.0 & 1231.0 & 1230.0 & 1032.0 & 1042.0 \\
\hline 0.725 & 1125.0 & 1119.0 & 1033.0 & 1028.0 & 793.4 & 803.1 \\
\hline 0.9935 & 743.4 & 731.8 & 730.5 & 714.5 & 689.8 & 657.6 \\
\hline $2 \cdot 1$ & 83.4 & 70.7 & 80.0 & 75.2 & 72.2 & 63.4 \\
\hline
\end{tabular}


ozone $=0.344$ atm $-\mathrm{cm}$, water vapor $=1.42 \mathrm{~cm}$, ground albedo $=0.2$, surface pressure $=1013 \mathrm{mb}$, and a turbidity at $0.5 \mu \mathrm{m}$ of 0.1 . The only differences for the horizontal spectra shown in Figure $4-2$ are that $Z=80.0^{\circ}$ and a turbidity of 0.51 was used.

Table 4-2. Diffuse Horizontal Spectral Irradiance Comparison of Dave Results with SPCTRAL2 Results for a Rayleigh Atmosphere with Molecular Absorption $\left(\mathrm{O}_{3}=0.31 \mathrm{~atm}-\mathrm{cm}, \mathrm{H}_{2} \mathrm{O}=2.93 \mathrm{~cm}\right)$

\begin{tabular}{|c|c|c|c|c|c|c|}
\hline \multirow[b]{2}{*}{$\lambda(\mu \mathrm{m})$} & \multirow{2}{*}{$\mathrm{Z}_{\text {Dave }}$} & \multirow{2}{*}{$\frac{\mathrm{Z}=60^{\circ}}{\text { SPCTRAL2 }}$} & \multicolumn{2}{|c|}{$\mathrm{Z}=80^{\circ}$} & \multirow[b]{2}{*}{ Dave } & \multirow[b]{2}{*}{ SPCTRAL } \\
\hline & & & Dave & SPCTRAL2 & & \\
\hline 0.31 & 75.5 & 94.9 & 21.5 & 28.5 & 1.1 & 0.8 \\
\hline 0.36 & 222.2 & 221.2 & 167.7 & 175.4 & 72.9 & 88.1 \\
\hline 0.415 & 234.5 & 227.7 & 199.8 & 198.0 & 118.0 & 124.6 \\
\hline 0.515 & 108.1 & 103.8 & 99.9 & 96.3 & 75.6 & 73.1 \\
\hline 0.615 & 46.6 & 44.9 & 43.7 & 42.1 & $34 \cdot 6$ & 33.0 \\
\hline 0.7035 & 23.4 & 22.6 & 22.7 & 21.8 & 20.6 & 19.3 \\
\hline 0.725 & 16.7 & 17.3 & 15.6 & 16.1 & 13.9 & 13.0 \\
\hline 0.9935 & 3.3 & 3.1 & 3.2 & 3.1 & 3.2 & 2.8 \\
\hline
\end{tabular}

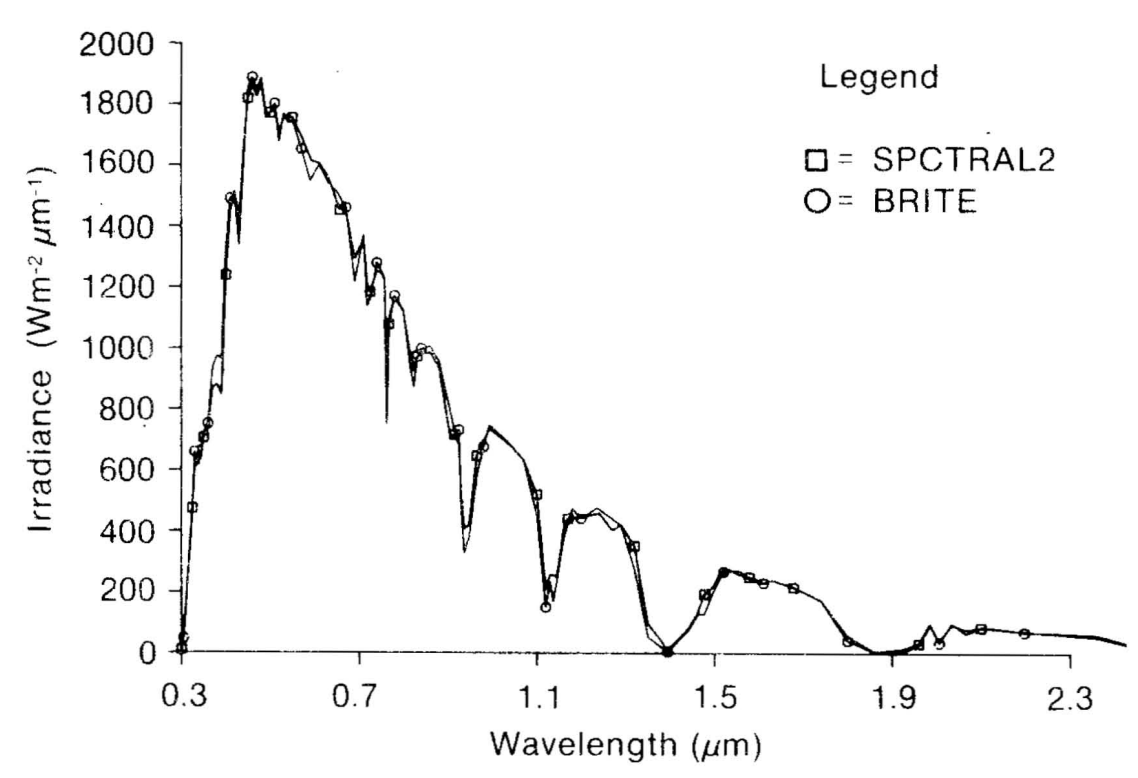

Figure 4-1. Comparison of Global Irradiance Calculated Using the SPCTRAL2 and BRITE Codes for $\tau_{a}(0.5 \mu \mathrm{m})=0.10, \mathrm{Z}=0^{\circ}$, and Tilt $=0^{\circ}$ 


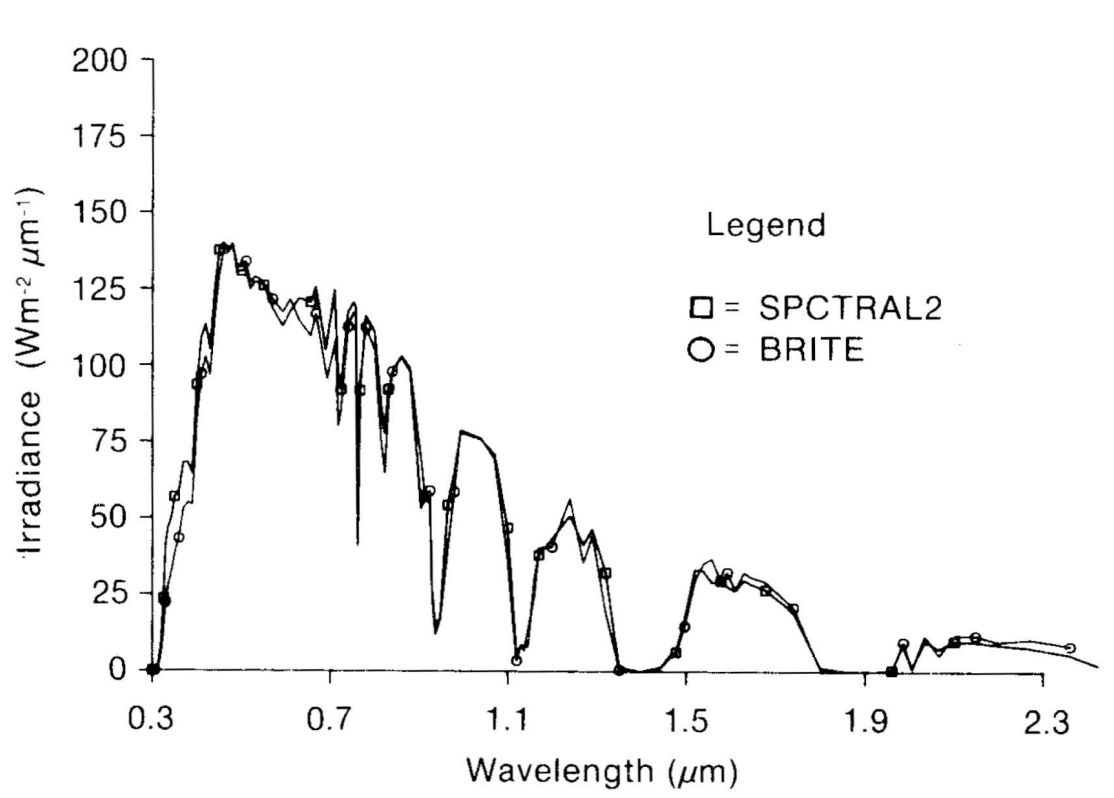

Figure 4-2. Comparison of Global Irradiance Calculated Using the SPCTRAL2 and BRITE Codes for $\tau_{a}(0.5 \mathrm{~mm})=0.51, \mathrm{z}=80^{\circ}$, and Tilt $=0^{\circ}$

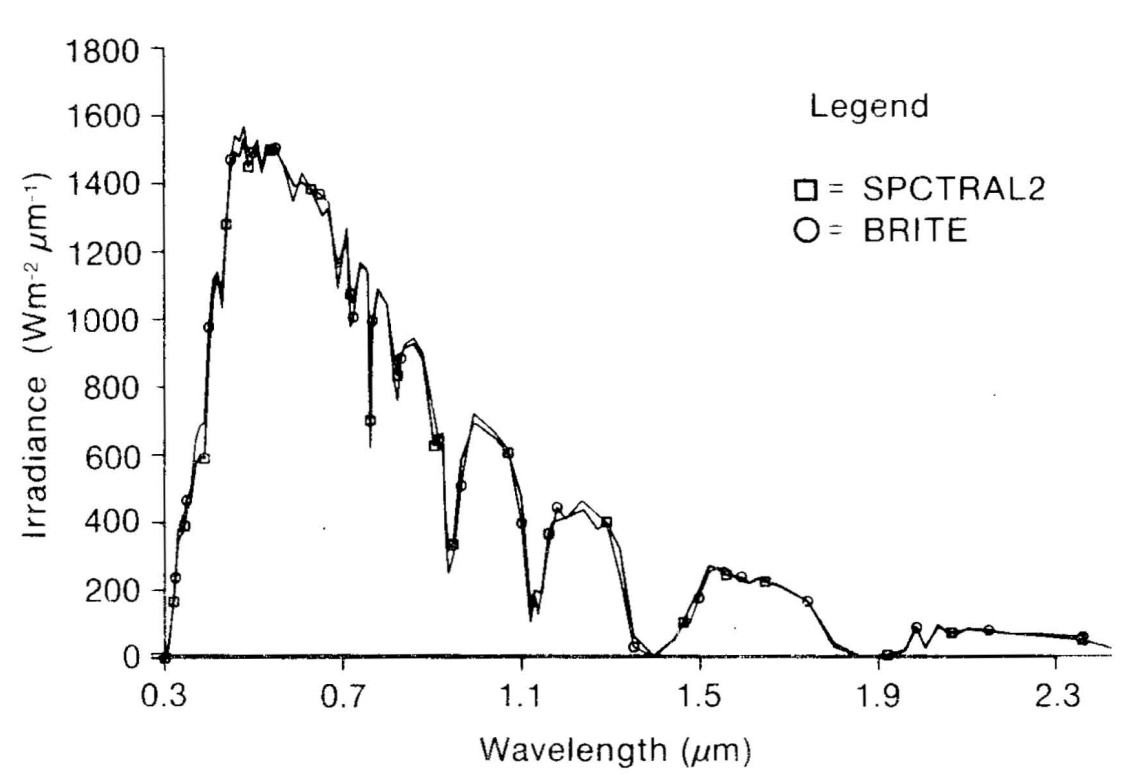

Figure 4-3. Comparison of Global Irradiance Calculated Using the SPCTRAL2 and BRITE Codes for $\tau_{a}(0.5 \mu \mathrm{m})=0.27, z=48.19^{\circ}$, and $\mathrm{Ti} 1 \mathrm{t}=37^{\circ}$ 


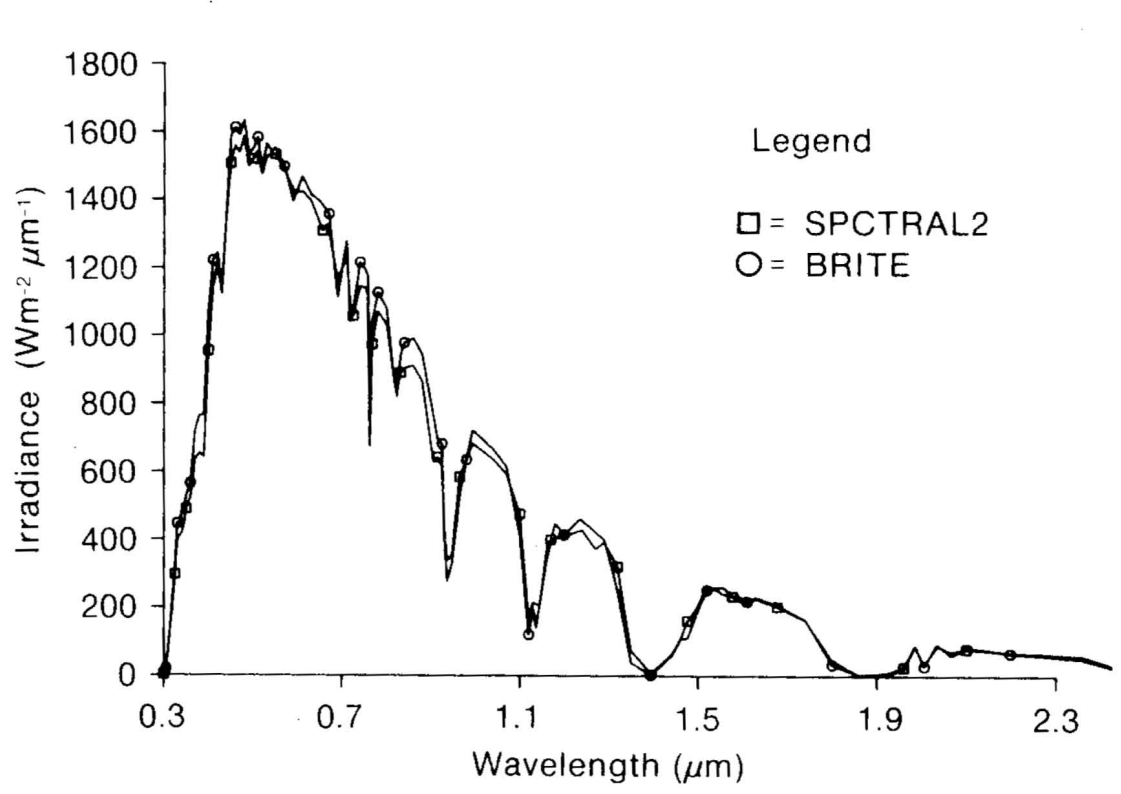

Figure 4-4. Comparison of Global Irradiance Calculated Using the SPCTRAL2 and BRITE Codes for $\tau_{\mathrm{a}}(0.5 \mathrm{~mm})=0.27, \mathrm{Z}=37^{\circ}$, and Tilt $=60^{\circ}$

Figure 4-3 is a comparison of BRITE and SPCTRAL2 results for a surface tilted $30^{\circ}$ from the horizontal for $Z=48.19^{\circ}$ and turbidity at $0.5 \mathrm{~m}$ of 0.27 . The spectra compared in Figure 4-4 were produced with the same parameters as those of Figure $4-3$, except $Z=37^{\circ}$ and the surfan $\because$ tilted $60^{\circ}$.

\subsection{COMPARISONS WITH MEASURED DATA}

The measured data used to make final adj. its to gaseous absorption coefficients in the model were taken with a ur. ie spectroradiometer $[27,28]$ and an automatic sun photometer $[29,30]$. Several comparisons between the spectra produced with the new simple spectral model and measured data are presented here to indicate the extent of agreement.

The first comparison was made with a global horizontal spectrum taken on 5 August 1981 in Golden, Colorado. This site is at $39.75^{\circ}$ north latitude and $105.156^{\circ}$ west longitude. The spectral measurement was made at 15:09 mountain standard time (MST), and the sun photometer measurements were made at fiveminute intervals throughout the day, as illustrated in Figures 4-5 and 4-6. The following parameters were determined:

$$
\begin{aligned}
& \text { Solar zenith angle }=44.8^{\circ} \\
& \text { Turbidity at } 0.368 \mu \mathrm{m}=0.39 \\
& \text { Turbidity at } 0.500 \mu \mathrm{m}=0.28 \\
& \text { Turbidity at } 0.862 \mu \mathrm{m}=0.13 \\
& \text { Precipitable water }=2.25 \mathrm{~cm} \\
& \text { Surface pressure }=329.6 \mathrm{mb} .
\end{aligned}
$$




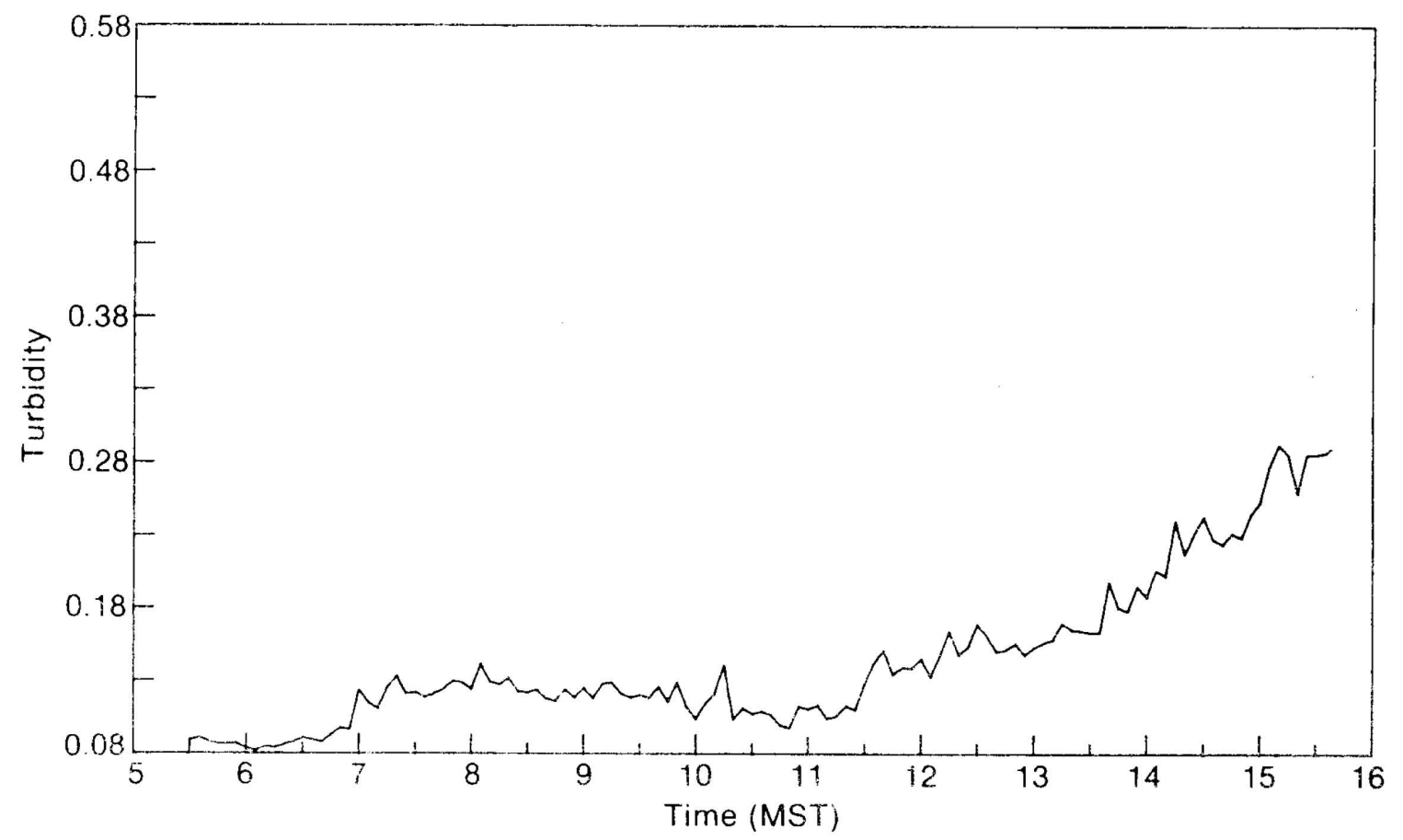

Pigure 4-5. Turbldity at 0.5 pris vs. Time of Day on 5 August 1981, Golden, Co

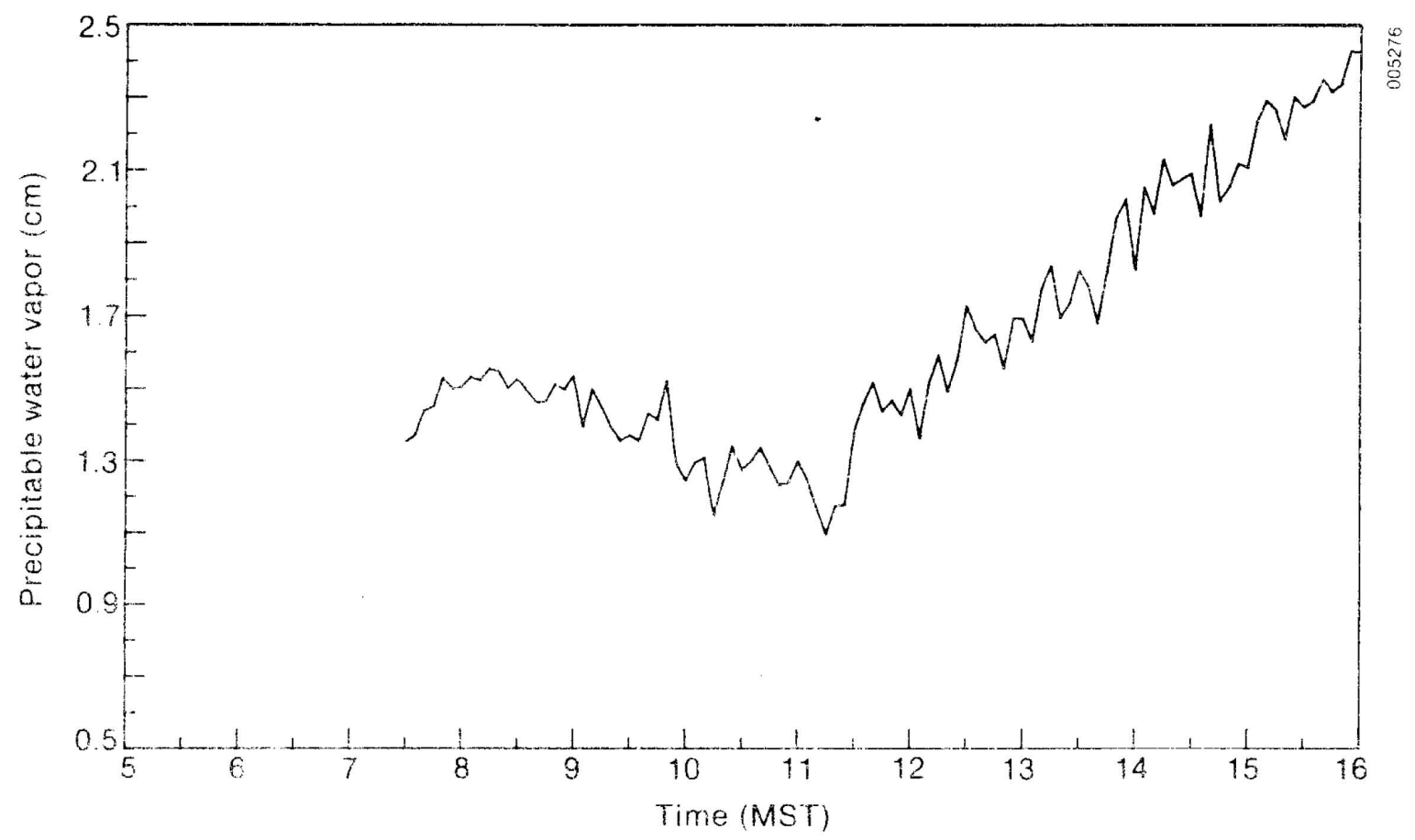

Rigure 4-6. Prectplabie water Yapor va. The of Day on 5 August 1981 , colders $c 0$ 
The rural aerosol model used in the BRITE code for a turbidity of 0.27 at $0.500 \mu \mathrm{m}$ wavelength produced turbidities of 0.37 at $0.368 \mathrm{~mm}$ wavelength and 0.14 at $0.862 \mathrm{um}$ wavelength. From this we can infer that the aerosol present during the 5 August measurement was nearly identical to that in the rural aerosol model, which adds validity to this particular comparison.

The ozone amount was assumed to be $0.31 \mathrm{~atm}-\mathrm{cm}$. The results of this comparison are shown in Figure 4-7, and the agreement between experiment and model is extraordinary. There is a slight wavelength calibration error evident in the measured data at the infrared end of the spectrum. This calibration error is due to the linear wavelength calibration procedure, which requires that a slope and intercept be determined. The spectroradiometer system determines both slope and intercept in real time in the visible wavelengths. In the infrared wavelengths, only the intercept is calibrated in real time; the slope appears to have changed slightly between laboratory calibration and the time the measurement was taken.

Several comparisons were also made on 19 August 1981. A global horizontal spectrum was measured at 10:44 MST, a direct normal spectrum was measured at 10:56 MST, and a global spectrum on a $40^{\circ}$ south tilt was measured at 13:42 MST. The atmospheric pressure was $832 \mathrm{mb}$ for these measurements. The meteorological and geometrical parameters are shown in Table 4-3 for these measurements.

Results of these comparisons are shown in Figures 4-8 through 4-10. The agreement between the modeled and measured data is very good for these data sets. One has to keep in mind that the circumsolar scattered radiation within a $6^{\circ}$ field-of-view (FOV) is included in the direct normal measurements. This could add $1 \%-5 \%$ to the irradiance in the $0.5 \mathrm{~m}$ region and could explain why the measured direct normal irradiance is larger. Differences similar in magnitude but in the opposite direction have been observed in measured and modeled diffuse radiation. The circumsolar radiation is missing in the diffuse measurement, which causes the opposite effect.

Table 4-3. Meteorological and Geometrical Parameters on 19 August 1981 at Golden, Colorado

\begin{tabular}{lccccc}
\hline Spectrum & $\begin{array}{c}\text { Zenith } \\
\text { Angle }\end{array}$ & $\begin{array}{c}\text { Turbidity } \\
0.368 \mu \mathrm{m}\end{array}$ & $\begin{array}{c}\text { Turbidity } \\
0.500 \mu \mathrm{m}\end{array}$ & $\begin{array}{c}\text { Turbidity } \\
0.862 \mu \mathrm{m}\end{array}$ & $\begin{array}{c}\mathrm{H}_{2} \mathrm{O} \\
(\mathrm{cm})\end{array}$ \\
\hline Global & $31.9^{\circ}$ & 0.180 & 0.149 & 0.042 & 1.36 \\
Direct & $30.8^{\circ}$ & 0.176 & 0.148 & 0.042 & 1.35 \\
Tilt & $34.66^{\circ}$ & 0.269 & 0.200 & 0.065 & 1.35 \\
\hline
\end{tabular}




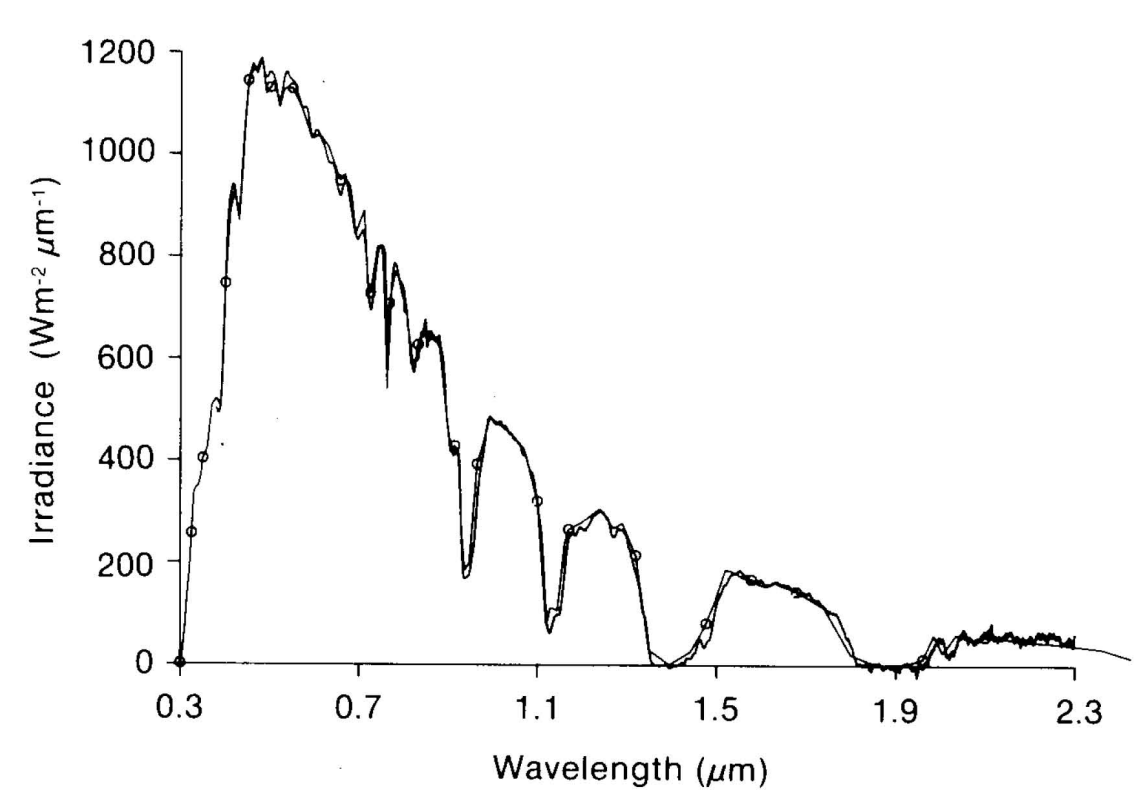

Figure 4-7. Comparison between Global Horizontal Irradiance Measured on 5 August 1981, Golden, CO, and Modeled Data Using SPCTRAL2 (o on the graph)

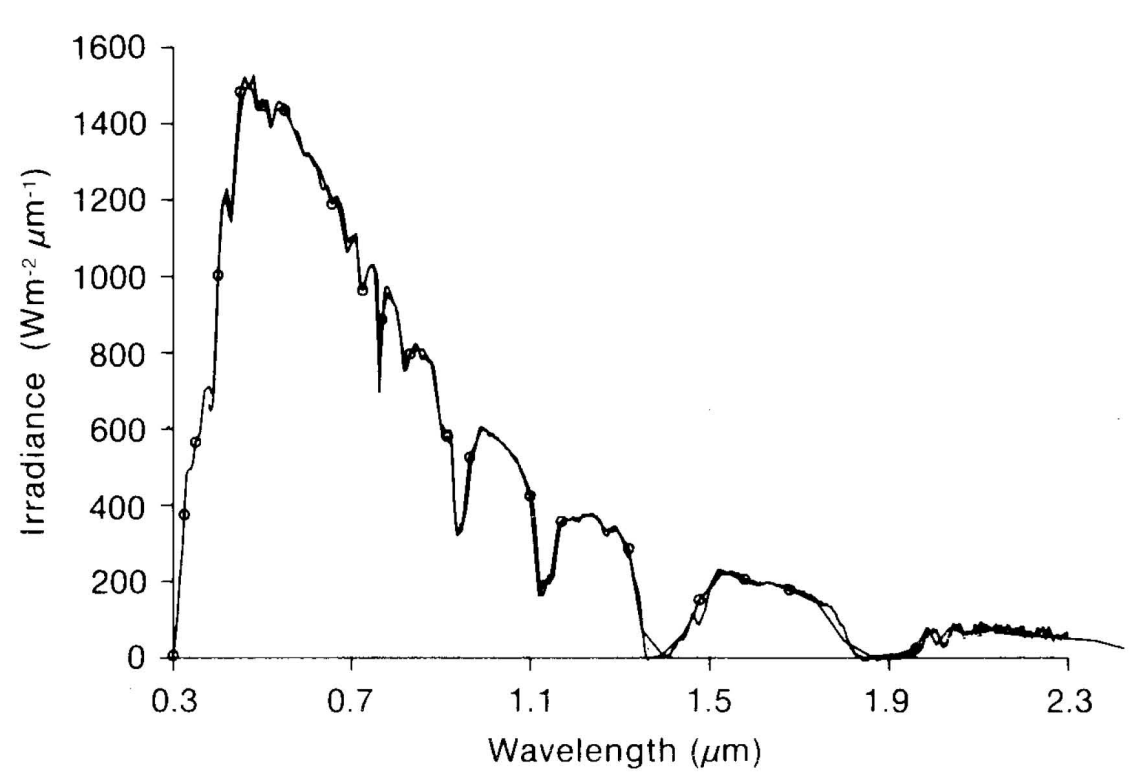

Figure 4-8. Comparison between Global Horizontal Irradiance Measured on 19 August 1981, Golden, Co, and Modeled Data Using SPCTRAL2 (o on the graph) 


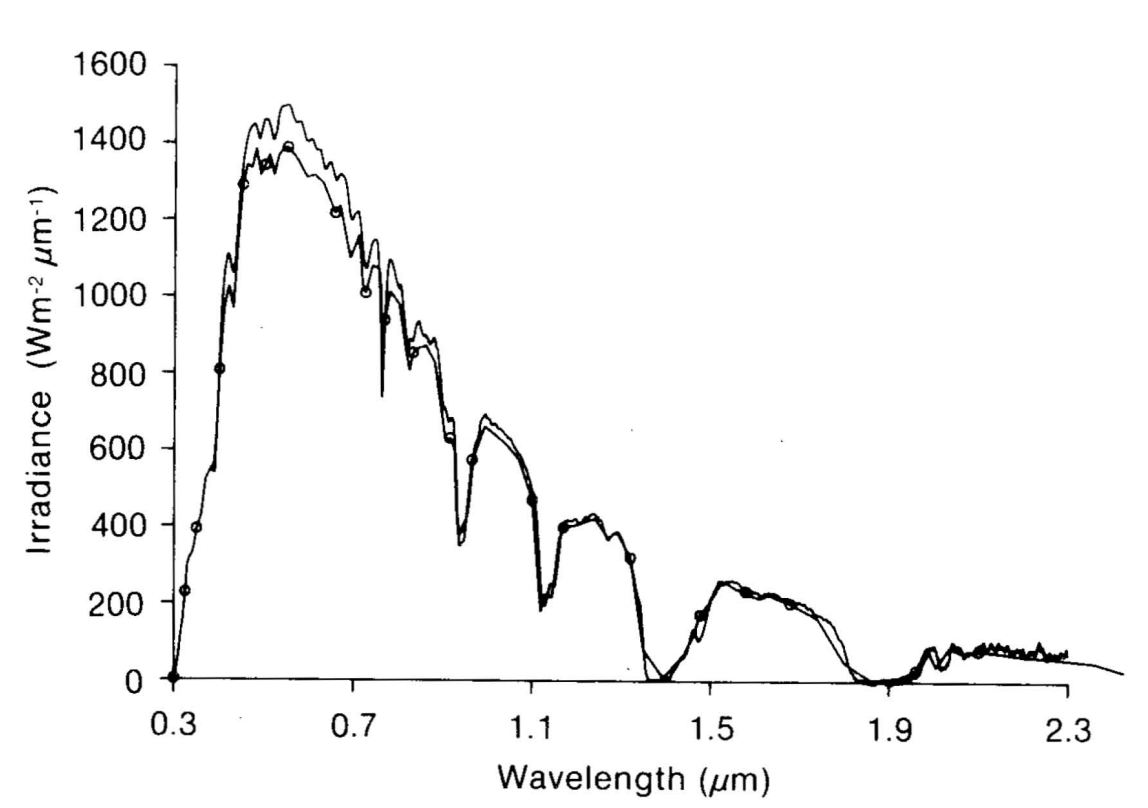

Figure 4-9. Comparison between Direct Normal Irradiance Measured on 19 August 1981, Golden, CO, and Modeled Data Using SPCTRAL2 (o on the graph)

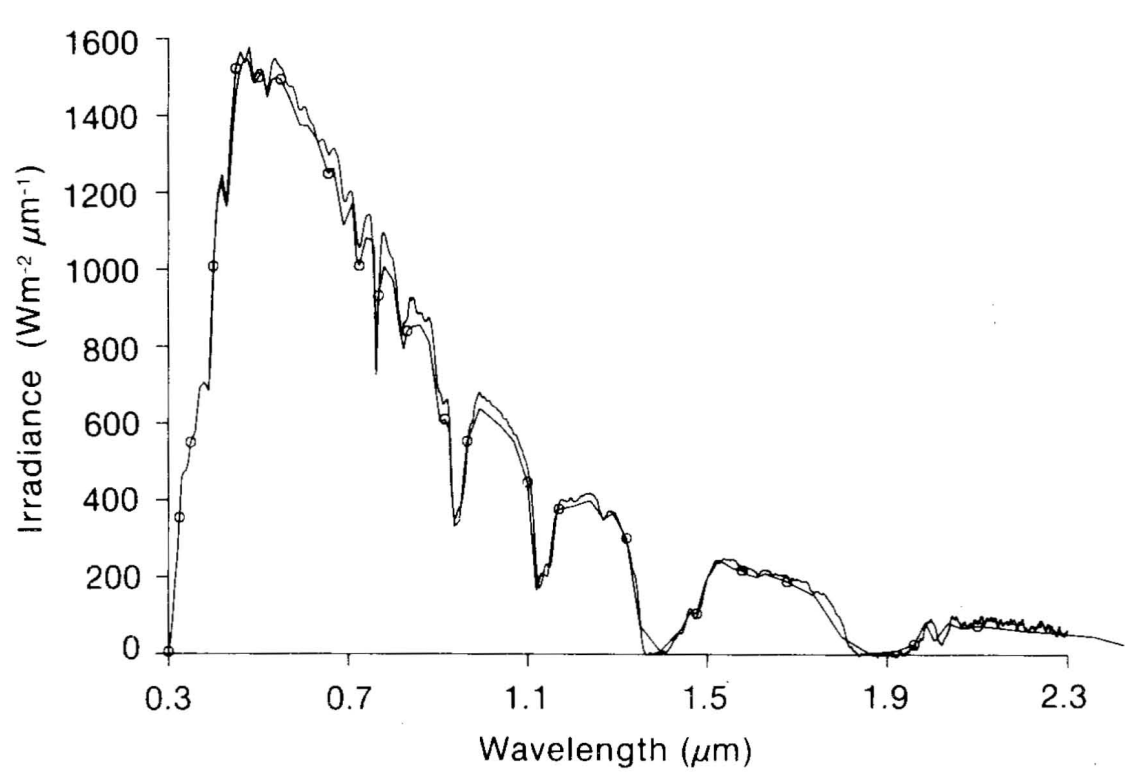

Figure 4-10. Comparison between Global Radiation on a South-Facing Surface Tilted 40 ${ }^{\circ}$, Measured on 19 August 1981, Golden, Co, and Modeled Data Using SPCTRAL2 (o on the graph) 
Another comparison (Figure 4-11) was made on 18 August 1981 at 13:22 hours for the global horizontal mode. The parameters for this measurement are as follows :

$\begin{array}{ll}\text { Solar zenith angle } & =30.11^{\circ} \\ \text { Turbidity at } 0.368 \mu \mathrm{m} & =0.320 \\ \text { Turbidity at } 0.500 \mu \mathrm{m} & =0.225 \\ \text { Turbidity at } 0.862 \mu \mathrm{m} & =0.069 \\ \text { Precipitable water } & =1.97 \mathrm{~cm} \\ \text { Surface pressure } & =830 \mathrm{mb} .\end{array}$

The agreement between modeled and measured data is not as good for this set of data. The reason for the disagreement is unknown, but possibly indicates the accuracy limitations of the modeled and the measured results. Additional measured data will be gathered in the future to verify the model and to assess the accuracy of modeled versus measured data comparisons. Justus and Paris have shown that the use of urban rather than rural aerosol parameters can account for differences of the magnitude and type shown in Figure 4-11. It is not known whether or not urban aerosols from nearby Denver, Colorado, were present during these measurements.

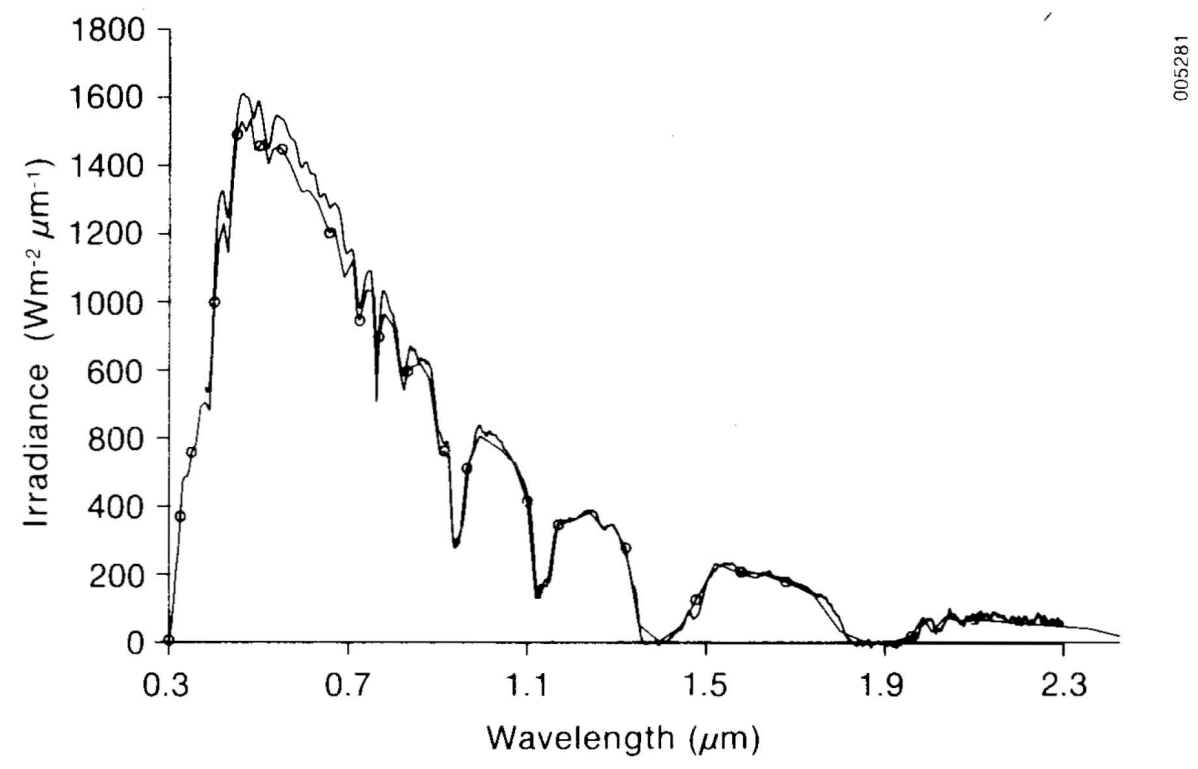

Figure 4-11. Comparison between Global Horizontal Irradiance Measured on 18 August 1981, Golden, CO, and Modeled Data Using SPCTRAL2 (o on the graph) 


\section{SECTION 5.0}

\section{EXAMPLES OF THE APPLICATION OF THE NEW SIMPLE SPECTRAL MODEL}

The primary goal of this work on simple spectral models is to give researchers the capability to calculate spectral irradiance using microcomputers. The spectra can then be used in models to evaluate solar device performance. For example, scientists can produce spectra by varying input parameters such as air mass, atmospheric turbidity and water vapor, and day of year, and use the spectra to examine the performance of spectrally selective photovoltaic devices under different conditions.

Examples of spectra generated using the simple model for clear days at the equinoxes and solstices and three different turbidity and water vapor combinations are shown in Figure 5-1. Spectra were calculated at 60-min intervals that are symmetrical about solar noon from sunrise to sunset. Only the morning spectra are plotted since the afternoon spectra are theoretically identical. These spectra were produced for a south-facing surface tilted $37^{\circ}$ from the horizontal at sea level for latitude $37^{\circ}$ and longitude $100^{\circ}$. The spectra may not be representative of a particular site, but serve as examples of differences in spectral irradiance under different conditions. Of note in these spectra are the effects of high turbidity and air mass on the visible portion of the spectrum and the difference in spectral content at different times of the year due to differences in air mass values.

These spectra can easily be converted to photon flux per wavelength or to photon flux per electron-volt if this format is more useful for particular applications. Examples of conversion results are shown in Figures 5-2 and 5-3. 


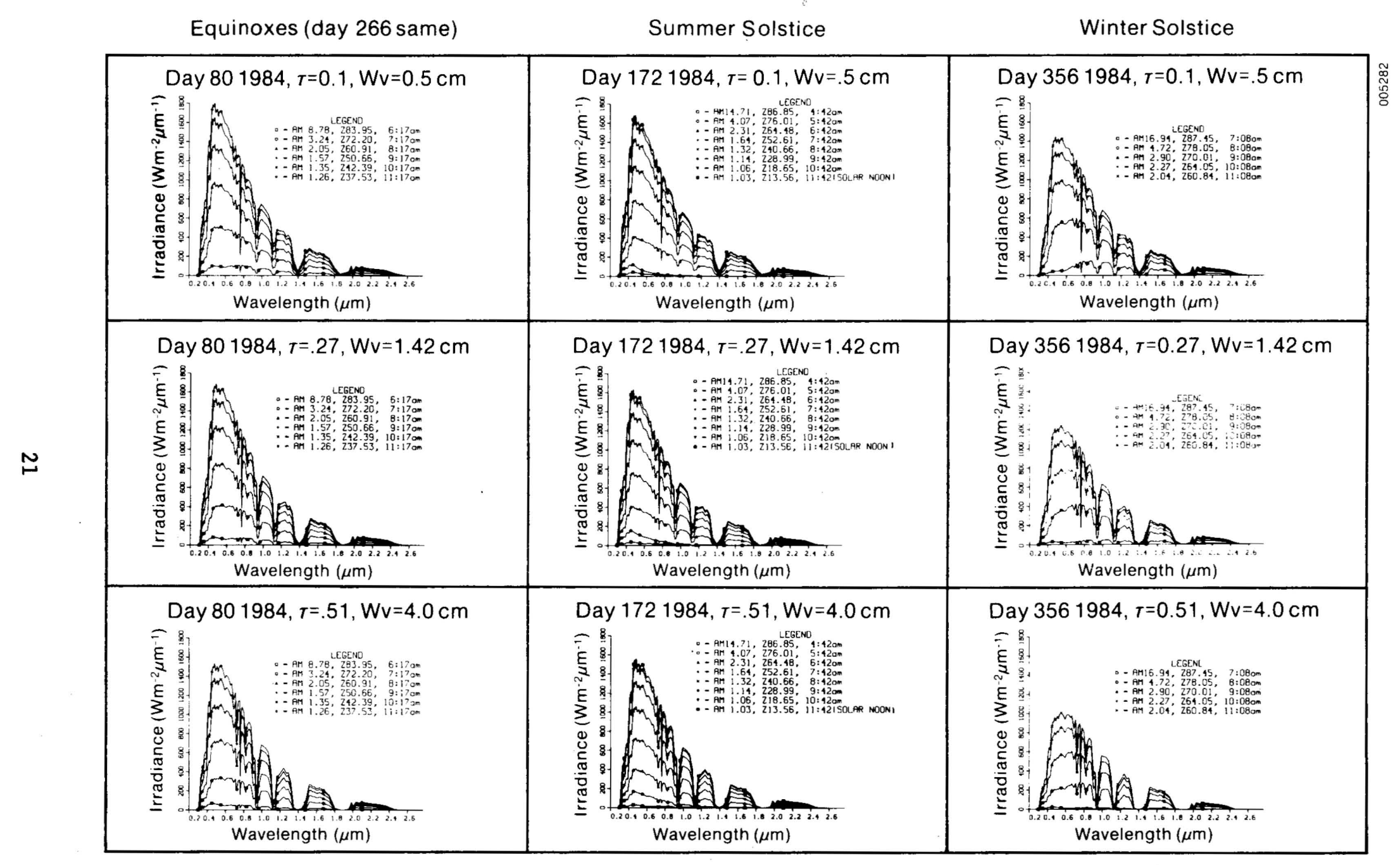

Figure 5-1. Global Irradiance on a South-Facing Surface Tilted $37^{\circ}$ for the Equinoxes (days 80 and 266 ) and for the Sumer and Winter Solstices (days 172 and 356). (AM is air mass and $Z$ is zenith angle.) 


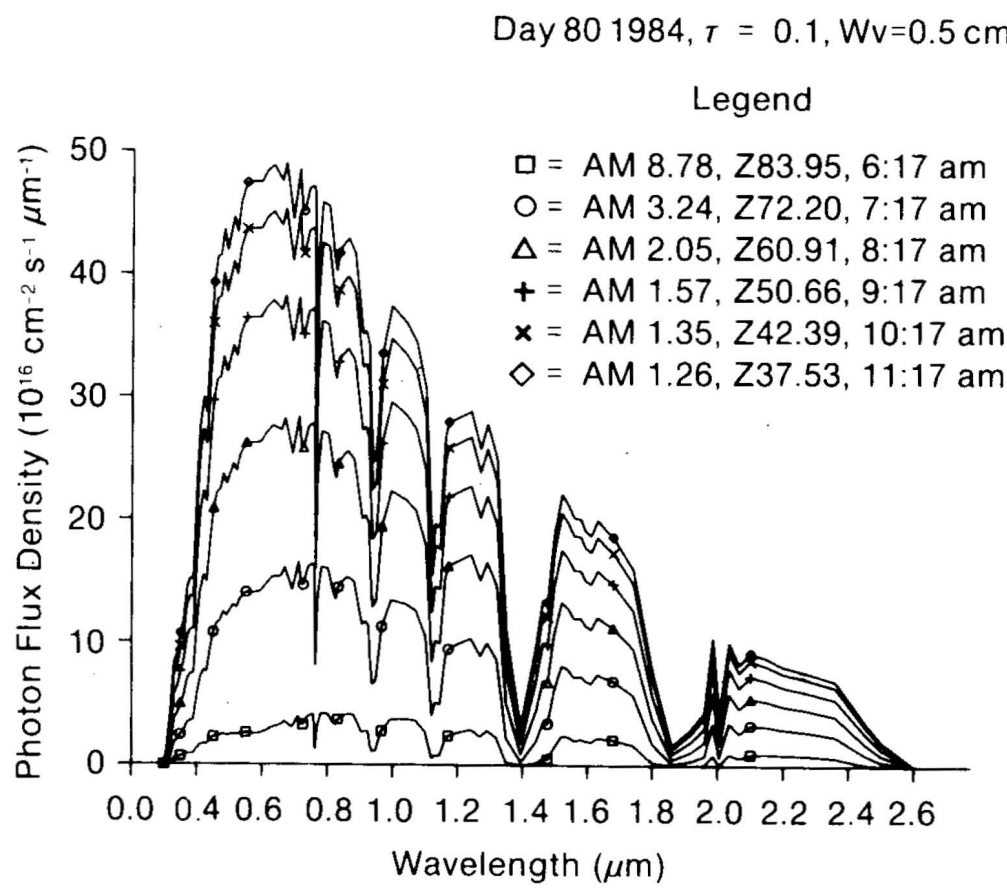

Figure 5-2. Photon Flux Density per Wavelength Interval Corresponding to Global Irradiance Shown in Figure 5-1 (day 80)

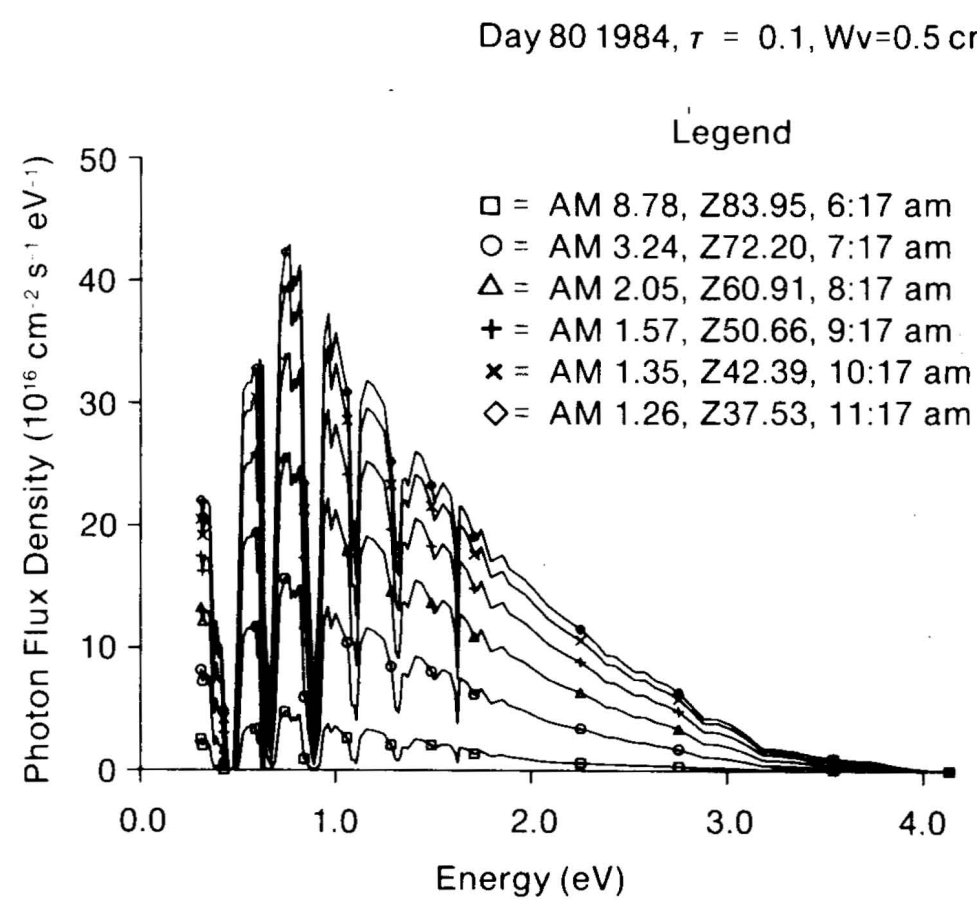

Figure 5-3. Photon Flux Density per Photon Energy Interval Corresponding to Global Irradiance Shown in Figure 5-1 (day 80) 


\section{SECTION 6.0}

\section{REFERENCES}

1. Bird, R. E., "A Simple Spectral Model for Direct Normal and Diffuse Horizontal Irradiance," Solar Energy, Vo1. 32, 1984, pp. 461-471.

2. Leckner, B., "The Spectral Distribution of Solar Radiation at the Earth's Surface--Elements of a Model," Solar Energy, Vo1. 20, 1978, pp. 143-150.

3. Brine, D. T., and M. Iqbal, "Solar Spectral Diffuse Irradiance Under Cloudless Skies," Solar Energy, Vo1. 30, 1983, pp. 447-453.

4. Justus, C. G., and M. V. Paris, "A Model for Solar Spectral Irradiance at the Bottom and Top of a Cloudless Atmosphere," submitted to J. of Climate and Applied Meteorology, 1984.

5. Hay, J. E., and J. A. Davies, "Calculation of the Solar Radiation Incident on an Inclined Surface," in Proceedings, First Canadian Solar Radiation Data Workshop, J. E. Hay and T. K. Won, eds., Toronto, Ontario, Canada, 1978.

6. Iqba1, M., An Introduction to Solar Radiation, New York: Academic Press, 1983, p. 101 .

7. Frohlich, C., and C. Wehrli, World Radiation Center, Davos, Switzerland, 1981, magnetic tape received by personal communication.

8. Necke1, H., and D. Labs, "Improved Data of Solar Spectral Irradiance from 0.33 to $1.25 \mu \mathrm{m}, "$ Solar Phys., Vol. 74, 1981, pp. 231-249.

9. Spencer, J. W., "Fourier Series Representation of the Position of the Sun," Search, Vo1. 2, 1971, p. 172.

10. Kneizys, F. X., E. P. Shettle, W. O. Gallery, J. H. Chetwynd, Jr., L. W. Abrea, J. E. A. Selby, R. W. Fenn, and R. W. McClatchey, Atmospheric Transmittance/Radiance: Computer Code LOWTRAN5, Tech. Rep. AFGL-TR-800067, Bedford, MA: U.S. Air Force Geophysics Laboratory, 1980.

11. Kasten, F., "A New Table and Approximate Formula for Relative Optical Air Mass," Arch. Meteorol. Geophys. Biochlimatol., Ser. B14, 1966, pp. 206-223.

12. Shettle, E. P., and R. W. Fenn, "Models of the Atmospheric Aerosol and Their Optical Properties," Proceedings of the Advisory Group for Aerospace Reseach and Development Conference No. 183, Optical Propagation in the Atmosphere, 1975, pp. 2.1-2.16. Presented at the Electromagnetic Wave Propagation Panel Symposium, Lyngby, Denmark; 27-31 October 1975.

13. Angstrom, A., "Technique of Determining the Turbidity of the Atmosphere," Tellus, Vol. 13, 1961, pp. 214-231. 
14. King, M. O., and B. M. Herman, "Determination of the Ground Albedo and the Index of Absorption of Atmospheric Particulates by Remote Sensing. Part I: Theory," J. of the Atmos. Sci., Vol. 36, 1979, pp. 163-173.

15. Van Heuklon, T. K., "Estimating Atmospheric Ozone for Solar Radiation Models," Solar Energy, Vo1. 22, 1979, pp. 63-68.

16. Bird, R. E., "Terrestrial Solar Spectral Modeling," Solar Cells, Vo1. 7; 1983, p. 107 .

17. Dave, J. V., International Business Machines Corporation, Palo Alto, CA, 1979. Copies of the data sets were put on magnetic tape. "Extensive Datasets of Diffuse Radiation in Realistic Atmospheric Models with Aerosols and Common Absorbing Gases," Solar Energy, Vol. 21, 1978, p. 361 .

18. Justus, C. G., Georgia Institute of Technology, Atlanta, Georgia, 1984, personal communication.

19. Liu, B. Y. H., and R. C. Jordan, "Dafly Insolation on Surfaces Tilted Towards the Equator," ASHRAE Journal, Vol. 3, 1961, pp. 53-59.

20. Becker, C. F., and J. S. Boyd, "Solar Radiation Availability on Surfaces in the United States Affected by Season, Orientation, Latitude, Altitude, and Cloudiness," Solar Energy, Vo1. 1, 1957, pp. 13-21.

21. Temps, R. C., and K. L. Coulson, "Solar Radiation Incident Upon Slopes of Different Orientations," Solar Energy, Vo1. 19, 1977, pp. 179-184.

22. Klucher, T. M., "Evaluation of Models to Predict Insolation on Tilted Surfaces," Solar Energy, Vo1. 23, 1979, pp. 111-114.

23. Ma, C. C. Y., and M. Iqbal, "Statistical Comparisons of Models for Estimating Solar Radiation on Inclined Surfaces" Solar Energy, Vo1. 31, 1983, pp. 313-317.

24. Smietana, Jr., P. J., R. G. Flocchini, R. L. Kennedy, and J. L. Hatfield, "A New Look at the Correlation of $\mathrm{K}_{\mathrm{d}}$ and $\mathrm{K}_{t}$ Ratios and at Global Solar Radiation Tilt Models Using One-Minute Measurements," Solar Energy, Vo1. 32, 1984, pp. 99-107.

25. Bird, R. E., and R. L. Hulstrom, Evaluation of Algorithms that Convert Measured Horizontal and Measured Direct Normal Irradiance Values to Irradiance Values on Tilted Surfaces, Golden, CO: Solar Energy Research Institute, forthcoming.

26. Perez, R., and R. Stewart, "Validation of an Anisotropic Model Estimating Insolation on Tilted Surfaces," Progress in Solar Energy, Vol. VII, American Solar Energy Society, 1984.

27. Kliman, A. W., and H. G. Eldering, "Design and Development of a Solar Spectroradiometer," Electro-Optical Systems Design, 1981, pp. 53-61. 
28. Bird, R. E., R. L. Hulstrom, A. W. Kliman, and H. G. Eldering, "Solar Spectral Measurements in the Terrestrial Environment," Applied Optics, Vo1. 21, 1982, pp. 1430-1436.

29. Bird, R. E., and R. L. Hulstrom, "Precipitable Water Measurements with Sun Photometers" J. Applied Met., Vol. 21, 1982, pp. 1196-1201.

30. Bird, R. E., and R. L. Hulstrom, "Reply," J. Climate Applied Met., Vol. 22, 1983, pp. 1969-1970. 


\section{APPENDIX}

\section{PROGRAM LISTING}

The FORTRAN 1isting of the computer program SPCTRAL2, used on a Control Data Corporation Cyber 750 computer, is presented here.

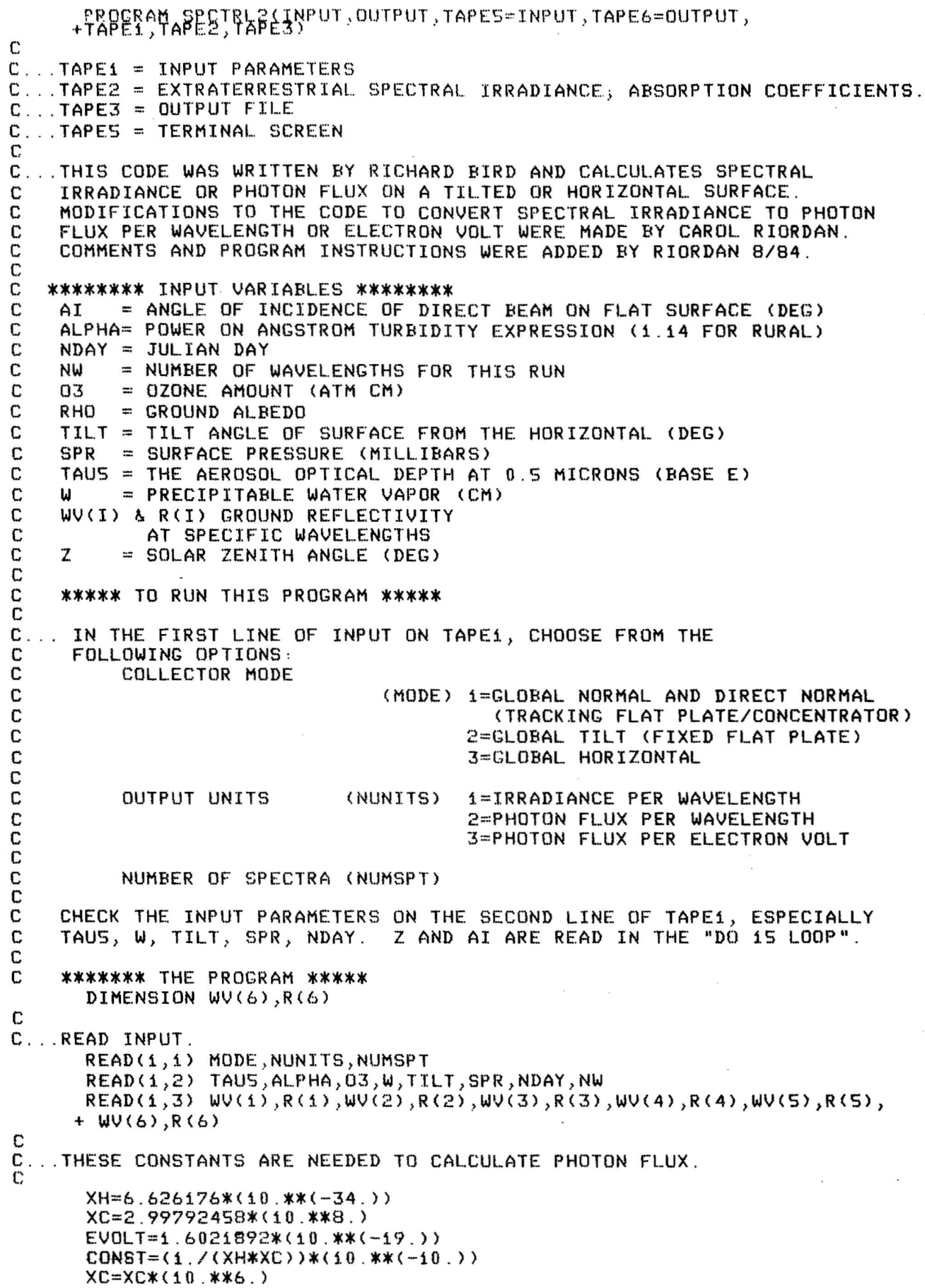




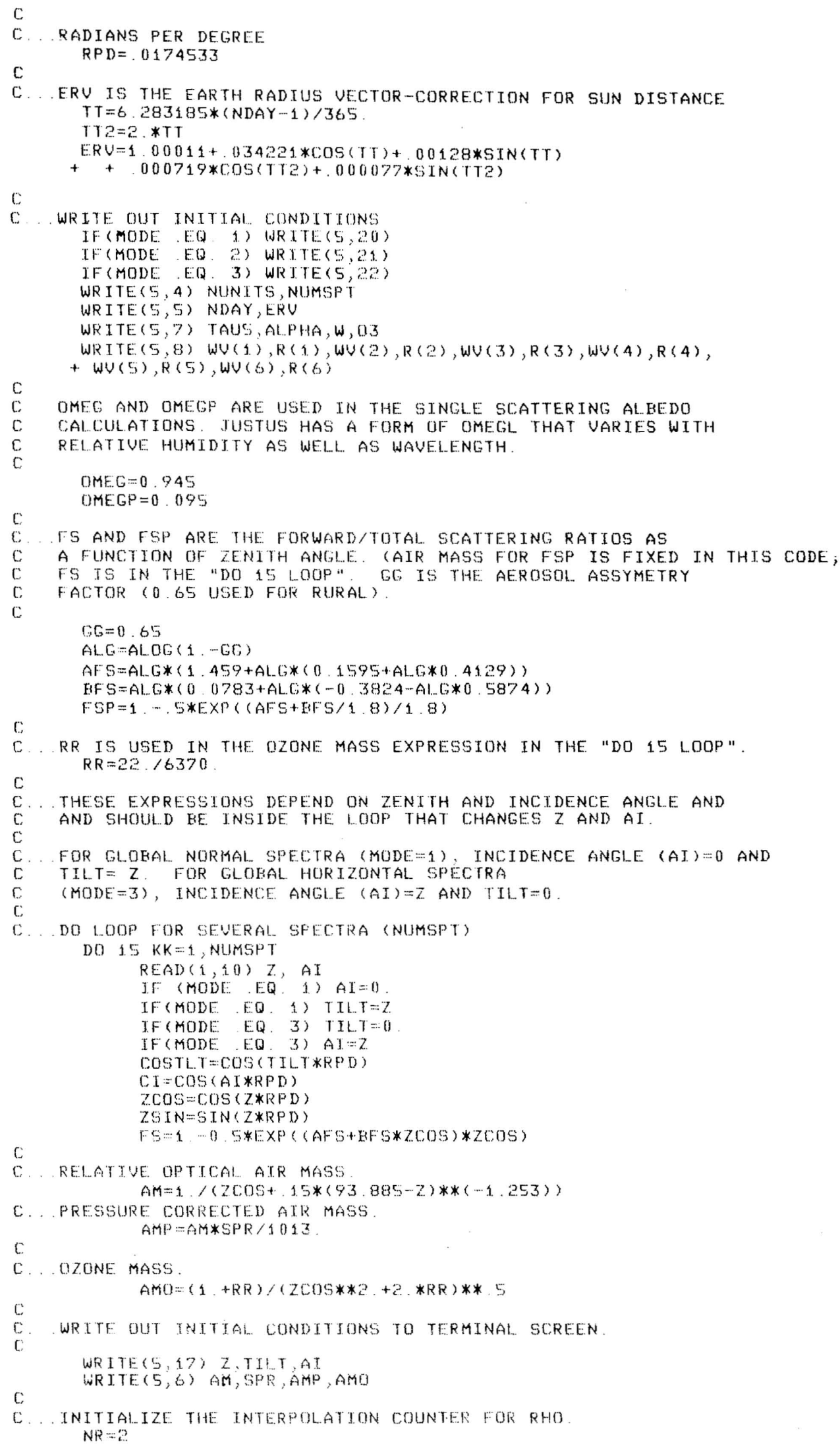


C. . REWIND THE TAPE WTTH ET SPECTRUM AND ABSORPTION COEFFTCIENTS FOR C EACH SPECTRUM

REWIND

$\mathrm{C}$

C. . DO LOOP FOR NUMEER OF WAUELENGTHS (NW)

DO $1.4 \quad I=1, N W$

C READ $(2,9)$ WUL, $H 0, A W, A O, A U$

C... CORRECT EXTRATERRESTRIAL. IRRADIANCE FOR EARTH RADIUS VECTOR.

c

C. $H 0=H O * E R V$

C. . OMEGL IS THE WAVELENGTH DEPENDENT SINGLE SCATTERTNG ALEEDO

$\mathrm{C}$ OMEGL $=O M E G * E X P(-O M E G P *(A L O G(W U L / 0,4)) * * 2$.

C.. THE FOLLOWING STATEMENTS PRODUCE THE WAVELENETH DEPENDENT ALBEDO c

C. . CALCULATE TRANSMITTANCE

IF (WVL. . GT . WV(NR)) $\quad N R=N R+1$

$S L P=(R(N R)-R(N R-1)) /(W V(N R)-W V(N R-1))$

$R H O=S L P *(W V L-W V(N R-1))+R(N R-1)$

$T R=\operatorname{EXP}(-A M P /(W V L * * 4 . *(115.6406-1.335 /$ WUL**2. $)))$

$T O=\operatorname{EXP}(-A 0 * 03 * A M O)$

$T W=\operatorname{EXP}(-.2385 * A W * W * A M /(1,+20.07 * A W * W * A M) * * .45)$

$T U=\operatorname{EXP}(-1.41 * A U * A M P /((1 .+118.93 * A U * A M P) * * .45))$

DEL.A $=$ TAIJ5* (WUL/. . $) * *(-A L$.PHA

$T A S=E X P\{-D M E G L * D E L A * A M)$

TAA $=\operatorname{EXP}(-11 .-O M E G$ G... $) * D E L A * A M)$

C $T A=E X P(-D E L A * A M)$

DIR $=$ HO*TR*TO*TW*TU*TA

C. . CALCULATE DIRECT COMPONENT OF IRRADIANCE ONTO SURFACE

DIRSUR =DIR $* C I$

C. . DRAY \& DAER HAVE BEEN MODIFIED GY EIRD. NOTE POWER ON TR TERM.

c

DRAY $=$ HO*ZCOS*TO*TW*TU*TAA*(1, -TR**.95)*.5

DAER $=H 0 * Z C O S * T O * T W * T U * T A A * T R * * 1.5 *(1,-$ TAS $) * F S$

TRP ‥EXP $(-1,8 /(W U L * * 4 . *(115.6406-1.335 /$ WUL **2) $))$

$T W P=\operatorname{EXP}(-.2385 * A W * W * 1.8 /((1 .+20.07 * A W * W * 1.8) * * .45))$

TUP $=\operatorname{EXP}(-1.41 * A \cup * 1.8 /((1 .+118.93 * A U * 1.8) * * .45))$

TASP $=\operatorname{EXP}(-O M E G L * D E L A * 1.8)$

TAAP $=\operatorname{EXP}(-(1,-O M E G L) * D E 1 . A * 1.8)$

RHOA=TUP*TWP*TAAP* $.5 *(1,-$ TRP $)+(1,-F S P) * T R P *(1,-T A S P))$

$D R G D=(D I R * Z C O S+(D R A Y+D A E R)) * R H O * R H O A /(1--R H O * R H O A)$

$D I F=D R A Y+D A E R+D R G D$

C. . CRC IS A UU CORRECTION FACTOR

C

$C \cdot R C=1.0$

IF (WVL... LE. 45) CRC=(WVL+ 55)**1.8

C. . DIFFUSE ON A HORIZONTAL. SURFACE

$D I F=D I F * C R C$

$\mathrm{c}$

C. . TOTAL ON A HORTZONTAL.. SURFACE

DTOT $=D$ DR $* Z C O S+D I F$

C. . MAKE DIFS=DIF TO USE FORMAT 12 FOR GLOKAL HORTZONTAL CASE.

DIFS $\cdots$ DIF

C

IF (MODE EQ. 3) GOTO 79

C. . GROUND REFLECTED COMPONENT .

C REFS D DTOT *RHO* (1.0 - COSTL.T )/2.0

C. . THE THREE FOLLOWING STATEMENTS ARE THE HAY TIL.T ALgORITHM

C. . ANISOTROPY INDEX.

AII $I=D I R / H O$

C. . CIRCUMSOLAR AND ISOTROPTC COMPONENT (WETGHTED BY DTFEAII AND DIF* $(1-A I T)$

DIFSC $=$ DTFAII $*$ CI $/ Z C O S$

DIFSI $=\mathrm{DTF} *(1,0-A \mathrm{~A}) *(1,0+\operatorname{COSTLT}) / 2.0$ 


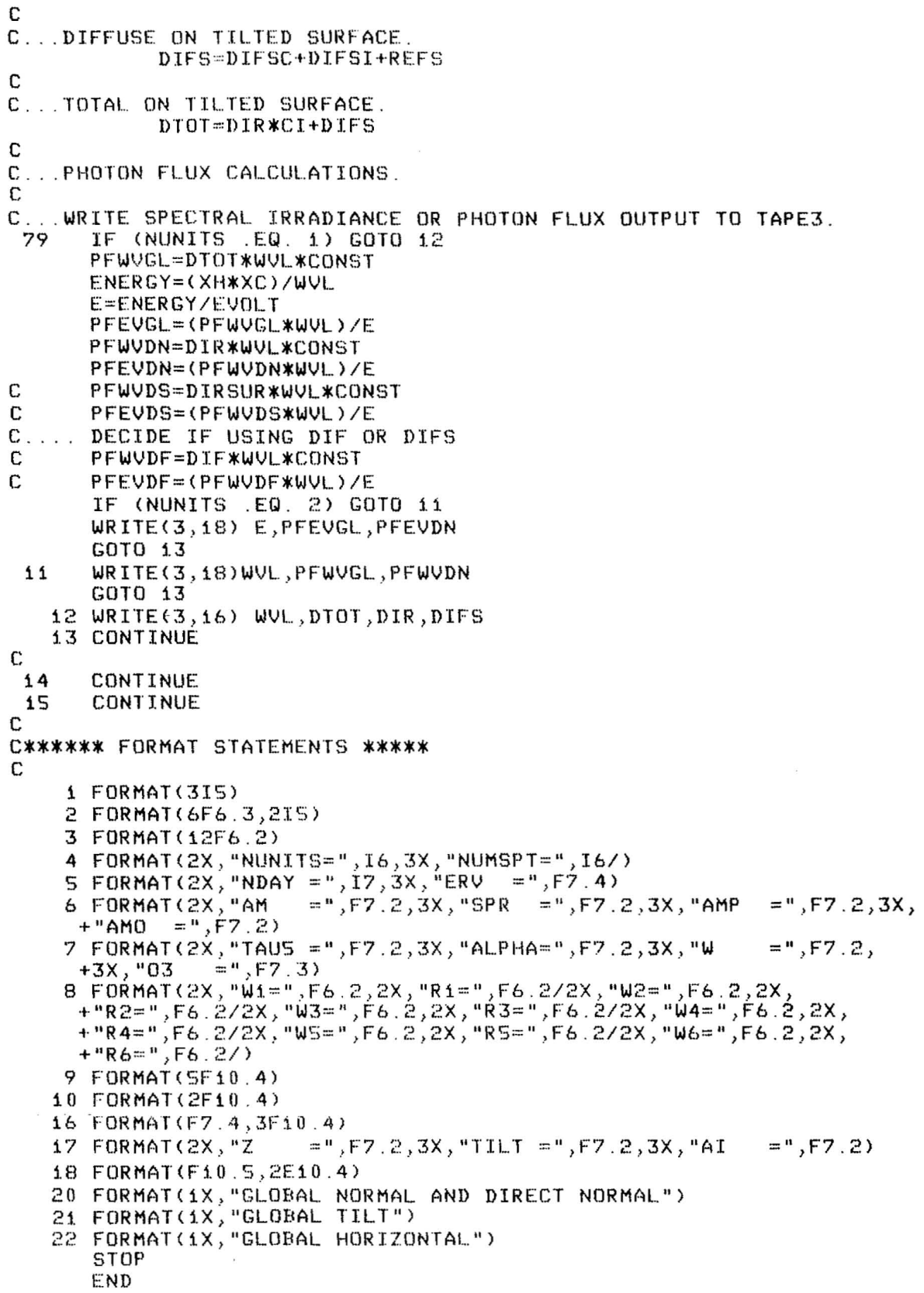




\begin{tabular}{|c|c|c|}
\hline $\begin{array}{l}\text { Document Control } \\
\text { Page }\end{array}$ & \begin{tabular}{|l|l|} 
1. SERI Report No. & 2. NTIS Accession No. \\
SERI /TR-215-2436 & \\
\end{tabular} & 3. Recipient's Accession No. \\
\hline \multirow{2}{*}{\multicolumn{2}{|c|}{$\begin{array}{l}\text { 4. Title and Subtitle } \\
\text { Simple Solar Spectral Model for Direct and Diffuse } \\
\text { Irradiance on Horizontal and Tilted Planes at the } \\
\text { Earth's Surface for Cloudless Atmospheres }\end{array}$}} & $\begin{array}{l}\text { 5. Publication Date } \\
\text { December } 1984\end{array}$ \\
\hline & & 6. \\
\hline \multicolumn{2}{|c|}{$\begin{array}{l}\text { 7. Author(s) } \\
\text { Richard Bird, Carol Riordan }\end{array}$} & 8. Performing Organization Rept. No. \\
\hline \multirow{2}{*}{\multicolumn{2}{|c|}{$\begin{array}{l}\text { 9. Performing Organization Name and Address } \\
\text { Solar. Energy Research Institute } \\
1617 \text { Cole Boulevard } \\
\text { Golden, Colorado } 80401\end{array}$}} & \multirow{2}{*}{$\begin{array}{l}\text { 10. Project/Task/Work Unit No. } \\
3414.10 \\
\begin{array}{l}\text { 11. Contract (C) or Grant (G) No. } \\
\text { (C) } \\
\text { (G) }\end{array}\end{array}$} \\
\hline & & \\
\hline \multirow{2}{*}{\multicolumn{2}{|c|}{ 12. Sponsoring Organization Name and Address }} & $\begin{array}{l}\text { 13. Type of Report \& Period Covered } \\
\text { Technical Report }\end{array}$ \\
\hline & & 14. \\
\hline \multicolumn{3}{|l|}{ 15. Supplementary Notes } \\
\hline \multicolumn{3}{|c|}{$\begin{array}{l}\text { This report presents a new, simple model for calculating clear-sky direct and } \\
\text { diffuse spectral irradiance on horizontal and tilted surfaces. The model is } \\
\text { based on previously reported simple algorithms and on comparisons with rigorous } \\
\text { radiative transfer calculations and limited outdoor measurements. Inputs to } \\
\text { the model include solar zenith angle, collector tilt angle, atmospheric } \\
\text { turbidity, amount of ozone and precipitable water vapor, surface pressure, } \\
\text { and ground albedo. The model calculates terrestrial spectra from } 0.3 \text { to } 4.0 \mu m \\
\text { with approximately } 10 \mathrm{~nm} \text { resolution. A major goal of this work is to provide } \\
\text { researchers with the capability to calculate spectral irradiance for different } \\
\text { atmospheric conditions and different collector geometries using microcomputers. }\end{array}$} \\
\hline \multicolumn{3}{|l|}{ - } \\
\hline \multicolumn{3}{|c|}{ 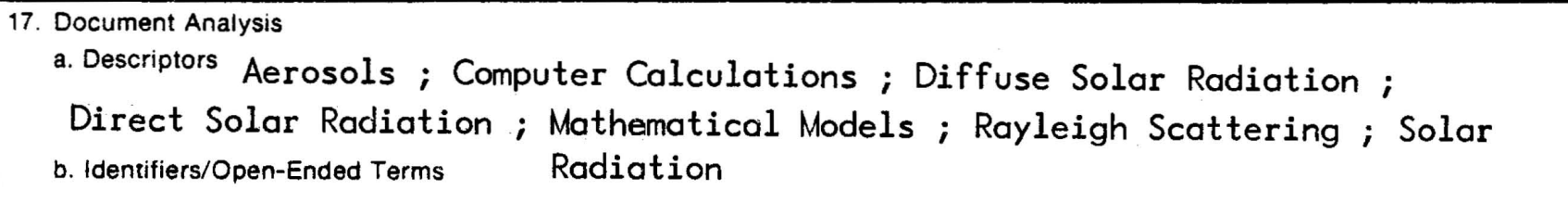 } \\
\hline \multicolumn{3}{|c|}{$59,61,62,63$} \\
\hline \multirow{2}{*}{\multicolumn{2}{|c|}{$\begin{array}{l}\text { 18. Availability Statement } \\
\text { National Technical Information Service } \\
\text { U.S. Department of Commerce } \\
5285 \text { Port Royal Road } \\
\text { Springfield, Virginia } 22161\end{array}$}} & $\begin{array}{l}\text { 19. No. of Pages } \\
37\end{array}$ \\
\hline & & $\begin{array}{l}\text { 20. Price } \\
\text { A03 }\end{array}$ \\
\hline
\end{tabular}

